\title{
Spatial contagion between financial markets: new evidence of asymmetric measures
}

\author{
Wafa Miled ${ }^{1} \cdot$ Zied Ftiti $^{2} \cdot$ Jean-Michel Sahut ${ }^{3}$ D
}

Accepted: 26 July 2021 / Published online: 1 September 2021

(c) The Author(s), under exclusive licence to Springer Science+Business Media, LLC, part of Springer Nature 2021

\begin{abstract}
The objective of this paper is to identify the presence, direction and time at which the pure contagion effect occurred between financial markets. In so doing, the aim is to prove the existence of both spatial and temporal asymmetries of pure contagion effects. Firstly, a new empirical framework is proposed in order to define a spatial contagion index using the conditional cumulative distribution function as a parameter to estimate a conditional copula. This methodology enables us to estimate a dynamic conditional copula, providing information about how the market sent pure contagion effects and when. Secondly, in addition to detecting the direction of contagion, the real-time contagion effect is determined, enabling us to calculate the delay of contagion effects (spillover) between financial markets. The present empirical results show the existence of both spatial and temporal asymmetry for bilateral contagion effects for 16 mature and emerging stock markets during the 2001-2018 period. This proves the importance of taking temporal asymmetry into account when we want to detect the contagion effect of every crisis and to estimate the period of pure contagion relating to investors' behaviors. Finally, these findings highlight the fact that contagion effects were more intensive during the subprime crisis than they were during the European debt crisis.
\end{abstract}

Keywords Spatial contagion · Copula $\cdot$ Financial time series $\cdot$ Asymmetric dependence

JEL Classification C31 C C32 $\cdot \mathrm{G} 15 \cdot \mathrm{E} 44$

Jean-Michel Sahut

jmsahut@gmail.com

1 GEF2A-Lab, Higher Institute of Management of Tunis, University of Tunis, Tunis, Tunisia

2 OCRE-Lab, EDC Paris Business School, France/University of Tunis, ISG-T, LR GEF2A, Tunis, Tunisia

3 IDRAC Business School, Lyon, France 


\section{Introduction}

Since the 1990s, the international financial environment has been characterized by a growing trend towards financial integration. This high-level integration is due to the massive development of international trade between the two halves of the globe, cross-border investments, and financial market deregulation (Batten et al., 2019). In particular, the degree of connectivity between mature and immature markets has risen sharply over the past two decades with capital flows. This has been the case with the integration of the BRICS with developed markets, since the BRICS are the major recipients of direct investment, and this group is one of the preferred destinations for global investors from major developed markets such as Canada, the E.U., Japan and the U.S. (Hadhri \& Ftiti, 2019; Naresh et al., 2018). Consequently however, this integration of markets provides the international backdrop for domestic crises (Corsetti et al., 2011).

These phenomena of contagion (Hübsch \& Walther, 2017), i.e. how an initial shock in one market can be transmitted to others, has been intensively explored by researchers because of the potential implications for policy makers. These researchers have mainly analyzed the transmission mechanisms of the crises and the existence of contagion phenomena across financial markets. Recently, a new strand of literature exploring spatial contagion has emerged (Fernandez, 2011). However, these studies have presented inconsistent findings, depending on the periods studied, the type of crisis, the countries included in analyses, etc. (Asgharian \& Nossman, 2011; Asgharian et al., 2013; Durante \& Foscolo, 2013; Durante et al., 2014, 2015; Tam, 2014; Weng \& Gong, 2016; Zorgati \& Lakhal, 2020). This lack of consistency in the results may be explained due to the fact of not considering both spatial and temporal asymmetries of the contagion effect between financial markets. Spatial asymmetry of contagion is defined as "the difference between the level of contagion transmitted or received by a financial market". Whereas, temporal asymmetry is "the change of the unidirectional or bidirectional contagion effect from one crisis to another".

The objective of this paper is to test the bilateral contagion behaviors between financial markets and to demonstrate the existence of both spatial and temporal asymmetries of contagion indexes. To do this, the presence, direction and time at which the pure contagion effect occurs are sought, in accordance with the precise definition of contagion proposed by Forbes and Rigobon (2002). These authors define contagion as "a significant increase in cross-market linkages after a shock in one country". Using this definition, this study aims to demonstrate the existence of both spatial and temporal asymmetries of pure contagion effects.

More precisely, this empirical study has two main aims. The first is to test the bilateral contagion effect. For this purpose, we adopt the proposition of Durante and Foscolo (2013), which takes into account the hypothesis of Durante et al. (2014) to find an optimal measure of contagion level (in accordance with the definition set out by Forbes and Rigobon (2002)). Beginning with the initiatives of Durante and Foscolo (2013) and Durante et al. (2014), this study seeks to identify the existence, direction and timing of contagion received and transmitted by every market. It begins by employing a conditional version of Durante and Foscolo's (2013) approach, before estimating the dynamic relationship between financial markets, proposing a dynamic conditional copula as a measure of bilateral dynamic dependencies.

The second important aim is to estimate the contagion effect of each crisis separately. This is done using the methodology of Carrion-I-Silvestre et al. (2009) combined with the test developed by Bai and Perron (2003) to examine the structural change of conditional 
dependence. At this level, the present methodology provides the opportunity to simultaneously verify the spatial and temporal asymmetries of contagion between the markets featured in the study sample. As such, this research contributes to previous studies measuring bilateral financial contagion by proposing a novel econometric measure which integrates all the features of currency crises. Asymmetric pure contagion indices, which include the asymmetry of unilateral linkage between financial markets, are computed. This asymmetric dynamics matrix can be used as a weighted matrix to study the spatial relationships among stock markets and to model dependencies using econometric spatial approaches (Weng \& Gong, 2016).

This paper makes four major contributions. Firstly, it investigates two forms of asymmetry of contagion: spatial asymmetry and temporal asymmetry, whereas the literature has so far only focused on the first form of (Zhang et al., 2020; Zorgati \& Lakhal, 2020). Secondly, it is the first paper to introduce the conditional empirical cumulative distribution function to estimate conditional copulas. This new empirical framework enables us to estimate a dynamic conditional copula and also provides information concerning how and when the market transmitted pure contagion effects. Thirdly, in addition to detecting the direction of contagion, the real-time contagion effect is defined, enabling us to identify the delay of contagion effects (spillover) between mature and immature markets. Fourthly, from an empirical perspective, the existence of both spatial and temporal asymmetry for bilateral contagion effects for the 16 mature and emerging stock markets of the sample is demonstrated for the 2001-2018 period. This proves the importance of taking into account the temporal asymmetry when seeking to detect the contagion effect of every crisis and to estimate the period of pure contagion relating to investors' behaviors. Finally, the present findings highlight how contagion effects were more intensive during the subprime crisis than they were during the European debt crisis.

The remainder of the paper is organized as follows. Section 2 reviews the literature on the subject of pure versus fundamentals-based contagion. Section 3 presents the empirical methodology used to test the contagion effect, the empirical specification of the problem and data. Section 4 discusses the empirical results, and Sect. 5 presents conclusions.

\section{Pure versus fundamentals-based contagion}

Interconnections between financial markets increase the level of contagion and intensify crisis effects on the international financial market, mainly in the form of a succession of crises. In the recent financial literature and the current international financial situation, crises are not strange phenomena (Jayech, 2016). In attempts to explain crisis scenarios, several concepts were proposed by recent financial theories such as spillover and contagion effects. In particular, the concept of "contagion effects" does not have a universal definition and is an ongoing subject of debate between researchers. For example, the definition of contagion phenomena as a crisis transmission mechanism creates confusion between spillover effects and contagion effects in that spillover effect incorporates both pure and fundamentals-based contagion (Claeys \& Vašíček, 2014). However, according to the contingency theory of crises, it is necessary to distinguish pure from fundamentals-based contagion (Ayadi et al., 2006). This difference has been widely discussed in the literature, exploring a wide variety of methods (Billio \& Pelizzon, 2003). So, this paper first presents a brief overview of some previous interesting propositions used to explain the transmission 
phenomenon of financial crises, then presents a new study on the presence of spatial and temporal asymmetries of contagion effects.

As mentioned above, in this work, contagion is defined as "a significant increase in cross-market linkages after a shock in one country" (Forbes \& Rigobon, 2002). However, for Bekaert et al. (2005), contagion is the excess of correlation rather than economic fundamental linkage. The big challenge is to identify the normal degree of dependence as opposed to an excessive degree, and to explain this according to fundamentals. Recently, Rigobon (2016) defined contagion as "the "unexpected" or "surprising" component of transmission of shocks across countries to other countries, as a change in behaviors during crises; and lately as purely any form of propagation across countries irrespective of the circumstances". Dornbusch et al. (2000) proposed the concept of fundamentals-based contagion to define the transmission effect explained by economic fundamentals. Lin et al. (1994) suggested the idea of pure contagion and attributed pure contagion to irrational investor behavior, which can lead to unexpected phenomena such as financial panics.

The financial literature relating to contagion can be divided into two strands. The first investigates transmission mechanisms between financial markets in order to identify channels of spillovers between markets. The second strand, which is more recent, aims to analyze the asymmetry of contagion effects across countries.

Contagion and transmission shock mechanisms have particularly attracted the interest of practitioners, academicians and policymakers alike following the Asian crisis of 1997. Baig and Goldfajn (1999) analyzed the contagion between the financial markets of Thailand, Malaysia, Indonesia, Korea, and the Philippines. Their findings supported evidence of cross-border contagion in the currency and equity markets. In addition to classical channels of inflation, exchange rate, FDI and trade, Engle (2009) demonstrated the existence of contagion channels relating to investors' behaviors when they trade on the international financial market. This seminal paper constitutes the starting point of many studies. Bekaert et al. (2014) confirmed Engle's findings, showing evidence of contagion from the US to the international market during the 2008 financial crisis. Along the same lines, Gómez-Puig and Sosvilla-Rivero (2016) highlighted the coexistence of "pure" and "fundamentals-based contagion" to interpret the spillover effect of the recent European debt crisis. Moreover, the propagation of stress to the portfolios of domestic investors was negatively correlated with the level of domestic economic fundamentals. Using the FIAPARCH model, Kenourgios and Dimitriou (2015) explained that the contagion effect between regional financial markets during the Lehman Brothers crisis limited the success of portfolio diversification strategies. Luchtenberg and $\mathrm{Vu}$ (2015) found that economic fundamentals such as trade, inflation rates, interest rates, regional effects, industrial production, and investors' risk aversion all contributed to international contagion during the 2008 crisis. Leung et al. (2017) tested pure and fundamentals-based contagion, finding that the spillover effects between London, Tokyo and New York stock markets with exchange rates could be explained by both pure (related to irrational investor behaviors) and fundamentals-based contagion (measured by macroeconomic fundamentals) during the global financial crisis and the European debt crisis. Finally, Kocaarslan et al. (2018) tested the contagion effect between the US and BRIC stock markets during the global financial crisis (GFC). Adding confirmation of the existence of both pure and fundamentals-based contagion to their findings, they underlined the importance of cross-market rebalancing channels for information transmission among US and BRICS markets.

A recent strand of literature has focused on the asymmetry of contagion effect in order to ensure optimal portfolio allocation, with appropriate diversification and hedging strategies. Ahmad et al. (2013) focused on the unilateral contagion effect from developed markets 
to BRICS immature markets. They demonstrated the divergence of effect related to the stress between transmitting and receiving markets. In particular, in the case of the European debt crisis, BRICS emerging markets were more affected by contagion from Ireland, Italy and Spain than from Greece. In contrast, analyzing the dynamic dependencies of the Chinese market on European markets during the European debt crisis period using the Kalman filter approach, Shen et al. (2015) found evidence of a low level of pure contagion.

From an econometric perspective, several methodologies have been used to analyze spatial asymmetry contagion between financial markets. Gjika and Horváth (2013) used a DCCGARCH model to test the presence of spatial asymmetry between European markets and affirmed a decrease in the benefit of portfolio diversification during stress periods with an increase in the level of dependence and the presence of pure contagion effects. Claeys and Vašíček (2014) suggested to use the model proposed by Diebold and Yilmaz (2009) combined with the multiple breakpoints test to estimate the spillover effects between European bond markets and to verify the presence of contagion effects during the sovereign debt crisis of 2011. Durante and Foscolo (2013) investigated the spatial contagion effect, defined as "a significant increase in co-movements of prices and quantities across markets, conditional on a crisis occurring in one market or group of markets". They proposed a new empirical framework based on the threshold copula approach, which aims to compare dependence between the tails and the central set. Durante et al. (2014) highlighted a new measure of contagion, consisting of quantifying the difference between dependence among financial time series in normal and stress periods. They extended Spearman's correlation coefficient to develop a conditional version, through parametric copulas (Gaussian, Student, Gumbel, SJC....). Moreover, through cointegration and error-correction modeling, Al Nasser and Hajilee (2016) examined the nature of dependencies between a group of mature and immature markets to prove the impact of both short-term and long-term dependencies between those markets on portfolio diversification. As such, they recommended that international investors should invest in emerging markets in addition to developed markets for long-term benefits. Weng and Gong (2016) proposed a Spatial Autoregressive error process and a dependence measure as a spatial weight matrix calculated using copula, but they only used a symmetric measure. Zhang et al. (2020) investigated the spatial spillover into G20 financial markets as well as the potential factors driving the systemic financial risk, without taken into account temporal asymmetry.

The above non-exhaustive summary of previous studies shows that abundant literature has investigated the transmission mechanism between markets in periods of turmoil. However, studies relating to the emerging literature on asymmetry of contagion between these countries are scarce. As this issue is useful for policymakers and investors (in particular for hedging strategies), this paper aims to contribute to the literature by investigating the pure contagion effect between immature and mature markets. More specifically, this paper proposes a new empirical framework in order to define a spatial contagion index using the conditional cumulative distribution function as a parameter to estimate conditional copula. This methodology enables us to estimate the dynamic conditional copula and provides information on how and when pure contagion effects occur. Secondly, in addition to identifying the direction of contagion, the real-time contagion effect is identified, enabling us to calculate the delay of contagion effects (spillover) between financial markets. 


\section{Methodology}

In order to test and discuss the presence of contagion effects between markets, the copula methodology was chosen to identify dependence levels, and a procedure to identify the existence of both spatial and temporal asymmetries for contagion effects is proposed herein. The empirical methodology is divided into two parts. First, the spatial direction of the financial contagion during the international financial crisis was taken into account using spatial asymmetric measures. This measure was developed from that presented by Durante and Foscolo (2013) based on the definition of contagion proposed by Forbes and Rigobon (2002). Here, the asymmetric aspect was introduced using a conditional empirical copula. This copula was calculated using the cumulative distribution function to estimate the empirical copula $(\mathrm{F}(\mathrm{X} / \mathrm{Y}))$ and the classical empirical distribution function $(\mathrm{F}(\mathrm{X}))$. Then, an asymmetric measure of Spearman's contagion indexes was calculated. An empirical conditional copula formulated using conditional empirical cumulative distribution function $(\mathrm{F}(\mathrm{X} / \mathrm{Y}))$ was used. This is arguably the first paper to use a conditional empirical distribution function to estimate an empirical copula, thus enabling us to test dependencies between financial markets.

For the second part of the methodology, as the contagion effect changes from one crisis to another, we propose applying the multiple breakpoints test to find the tail dependence between financial markets estimated using a conditional dynamic Gaussian copula to detect the structural change. We use the dynamic Gaussian copula because it measures the dependencies between the whole distribution functions. By doing this, we will be able to detect the moment when the contagion effect was present, which corresponds to the moment when dependencies increased across the whole distribution series. So, we can identify the pure contagion of each crisis separately where it exists. Following this, the steps taken in the estimations are presented.

\subsection{Steps of estimation}

This section sets out the steps followed to verify the presence of contagion effects between financial markets using static and dynamic conditional copulas. In this first stage, in order to respect the defined field condition for using copula modeling, ARMA-GARCH models were estimated for every stock market return to eliminate and data. Section 4 discusses and data. Section 4 discusses problems.

\subsubsection{ARMA-GARCH modeling}

The Copula measure was defined for a random walk $[0,1]$. To do this, randomized stock market returns were first used, followed by ARMA-GARCH modeling to screen autocorrelation and Arch effects from returns.

In general, the ARMA-GARCH model is defined as follows:

$$
\begin{gathered}
y_{t}=\mu+\sum_{i=1}^{p} \varphi_{i} y_{t-i}+\sum_{j=1}^{q} \theta_{j} \varepsilon_{t-j}+\varepsilon_{t}, \varepsilon_{t} \approx N\left(0, \sigma_{t}^{2}\right) \\
\sigma_{t}^{2}=\omega+\sum_{i=1}^{r} \beta_{i} \sigma_{t-i}^{2}+\sum_{j=1}^{s} \alpha_{i} \varepsilon_{t-j}^{2}
\end{gathered}
$$




$$
\varepsilon_{t}=\sigma_{t} z_{t}, \quad z_{t} \approx N(0,1)
$$

The residuals of the above ARMA-GARCH estimations were thus discovered. ${ }^{1}$ The contagion indexes were first estimated, based on the conditional static empirical copula. The next section presents the steps followed to calculate the contagion index.

\subsubsection{Measure of spatial contagion}

This paper adopts the approach proposed by Durante and Foscolo (2013), further contributing to the literature by introducing the hypothesis of spatial asymmetry ${ }^{2}$ of the contagion measure. So, we can distinguish the direction of contagion effects between two markets $\mathrm{X}$ to $\mathrm{Y}$. Indeed, we can try to identify the presence of asymmetry of contagion to confirm the difference between contagions transmitted and received. To do this, the effect of every shock is studied separately using dynamic tail dependence based on copula measures.

3.1.2.1 Definition of a copula based on the Sklar proposal This stage began with the Sklar (1959) proposal, wherein the conditional copula is defined as follows (Patton, 2006, 2012 and 2013):

Let us consider that $\mathrm{X}, \mathrm{Y}$ and $\mathrm{Z}$ are three random variables, the conditional copula $(X, Y \mid Z)$ is the joint distribution $H_{z}(. \mid Z)=z$. The conditional distribution function can be defined as $U_{1} \equiv F_{1 \mid z}(X \mid Z)$ and $U_{2} \equiv F_{2 \mid z}(Y \mid Z)$.

$$
C(X, Y \mid Z)=C\left(F_{1 \mid z}(X \mid Z), F_{2 \mid z}(Y \mid Z) \mid z\right)
$$

where $\mathrm{Z}$, is the volatility of the market X.z is the support of Z.

In accordance with the definition set out by Forbes and Rigobon (2002) to estimate the contagion level, we calculate conditional empirical distribution functions. After this, in order to compare the levels of dependence during periods of crisis and calm, extreme values are separated from values of the calm period. Then, we subdivide the conditional empirical distribution function into two subgroups as follow:

Let us consider that $(\Omega, F, P)$ is a probabilistic space, we define two random variables $(\mathrm{X}, \mathrm{Y})$. The threshold copula of the couple $(\mathrm{X}, \mathrm{Y})$ for $(\mathrm{X}, \mathrm{Y}) \in \mathrm{B}$ is defined as:

For $(\mathrm{X}, \mathrm{Y})$ returns of two stock market indexes. The two subsets of $B \in \bar{R}^{2}$

- $T_{\alpha_{1}, \alpha_{2}}=\left[-\infty, q_{x}\left(\alpha_{1}\right)\right] *\left[-\infty, q_{y / x}\left(\alpha_{2}\right)\right]$

- $M_{\beta_{1}, \beta_{2}}=\left[q_{x}\left(\beta_{1}\right), q_{x}\left(1-\beta_{1}\right)\right] *\left[q_{y / x}\left(\beta_{2}\right), q_{y / x}\left(1-\beta_{2}\right)\right]$

where

- $\alpha_{1}, \alpha_{2}, \beta_{1}$ et $\beta_{2} \in\left[1, \frac{1}{2}\right]^{2}$

- $q_{x} \wedge q_{y / x}$ are the quantile functions associated with $\mathrm{x}$ and $\mathrm{y}$.

Let us consider in the set $B \in \bar{R}^{2}$ that $P((X, Y) \in B)>0$

\footnotetext{
1 The GARCH extension models used are the TGARCH, EGARCH and APARCH.

${ }^{2}$ Using a conditional copula to detect the direction of contagion.
} 
In this work, the proposal set out by Durante and Foscolo (2013) where $\alpha=\beta=0.1^{3}$ is used. Thus, the two copulas $C_{T_{\alpha}}$ and $C_{M_{\alpha}}$ are defined as follows:

$C_{T_{\alpha}}$ is the copula defined for the distribution function in the interval and corresponds to the measure of dependency between tail sets:

- $T_{\alpha}=\left[-\infty, q_{x}(\alpha)\right] *\left[-\infty, q_{y / x}(\alpha)\right] C_{M_{\alpha}}$ is the copula defined for the distribution function in the interval and corresponds to the measure of dependency between medium sets:

- $M_{\alpha}=\left[q_{x}(\alpha), q_{x}(1-\alpha)\right] *\left[q_{y / x}(\alpha), q_{y / x}(1-\alpha)\right]$

3.1.2.2 Spearman's contagion indexes To test the contagion effect, Spearman's Rho is used, based on the conditional copula above. However, in practice, conditional Spearman contagion indexes are calculated following the above steps.

Firstly, we begin by measuring the conditional correlation indexes $\rho$ for the lower tail and the central set of the distribution, defined as follows:

$$
\rho(C)=12 \int_{[0,1]^{2}} C(x, y \mid z) C(x, y \mid z)-3
$$

To compute the contagion indexes, we compare the two threshold copulas of the central set and lower tail of the distribution. Using the two copulas $C_{T}$ and $C_{M}$, we verify the presence of contagion effect with the following test:

- $H_{0}: \rho\left(C_{T_{\alpha}}\right) \leq \rho\left(C_{M_{\alpha}}\right)$ : Absence of pure contagion effect

- $H_{1}: \rho\left(C_{T_{\alpha}}\right)>\rho\left(C_{M_{\alpha}}{ }^{\alpha}\right)$ : Presence of contagion effect

The SCI contagion indexes will be calculated from the two levels of dependence during the extreme (lower tail dependence) and calm periods. This index is defined as:

$$
S C I_{\alpha}=\frac{\rho\left(C_{T_{\alpha}}\right)-\rho\left(C_{M_{\alpha}}\right)}{2}
$$

To discuss the result of the contagion indexes measured, we refer to the thresholds proposed in the work of Durante and Foscolo (2013). Here, the following rules (applying the test presented below) must be respected:

- If the $S C I_{\alpha}=0$ or $\rho\left(C_{T_{\alpha}}\right)=\rho\left(C_{M_{\alpha}}\right)$, then the situation will not change during crash periods: this signifies the absence of contagion effect.

- If the $S C I_{\alpha}<0$, or $\rho\left(C_{T_{\alpha}}\right)<\rho\left(C_{M_{\alpha}}\right)$, then the dependency during the crisis will not increase during the stress period, and we can reject the hypotheses of the presence of pure financial contagion effects.

These two conditions correspond to the $H_{0}: \rho\left(C_{T_{\alpha}}\right) \leq \rho\left(C_{M_{\alpha}}\right)$ of the test of presence of pure contagion effects presented below.

- If the $S C I_{\alpha}>0$, this signifies that $\rho\left(C_{T_{\alpha}}\right)>\rho\left(C_{M_{\alpha}}\right)$ (this corresponds to the $H_{1}$ of the test presented below), and we can accept the hypothesis of financial contagion.

\footnotetext{
${ }^{3}$ Carol (2008) argues that $10 \%$ of tail can be set to obtain a reasonably accurate estimate of tail parameters, provided that the sample is large enough (more than 2000 observations)
} 
Then, we proceed to estimate conditional dynamic SJC copulas in order to verify the increase in dependence during a stress period in comparison with a calm period, given its ability to consider asymmetry in dependencies between tails.

3.1.2.3 The definition of the SJC copula The Clayton copula is proposed in the literature to measure dependence for the lower tail. The first modification of the Clayton copula was proposed using the Laplace transform to estimate both lower and upper tails. The Joe-Clayton copula is:

$$
\begin{aligned}
& C_{J C}\left(x, y \mid \tau^{U}, \tau^{L}\right)=1-\left(1-\left\{\left[1-(1-x)^{k}\right]^{-\gamma}+\left[1-(1-y)^{k}\right]^{-\gamma}-1\right\}^{\frac{-1}{\gamma}}\right)^{\frac{1}{k}} \\
& \kappa=\frac{1}{\log _{2}\left(2-\tau^{U}\right)}, \gamma=\frac{-1}{\log _{2}\left(\tau^{L}\right)} \cdot \tau^{U} \in(0,1) \text { and } \tau^{L} \in(0,1) \text { are the measures of upper and } \\
& \text { lower tail dependencies respectively. }
\end{aligned}
$$

SJC copula (Patton, 2006): A modification of the Joe-Clayton (JC) copula

The SJC copula introduces the independence between the upper and the lower tail to test the presence or absence of asymmetry. The generalized density of the dynamic SJC-Copula is:

$$
C_{t}^{S J C}\left(x, y \mid \tau^{U}, \tau^{L}\right)=0.5\left[C_{J C}\left(x, y \mid \tau^{U}, \tau^{L}\right)+C_{J C}\left(1-x, 1-y \mid \tau^{U}, \tau^{L}\right)+x+y-1\right]
$$

And the tail dependences are:

$$
\begin{aligned}
& \tau_{t}^{U}=\prod\left(\beta_{U}^{S J C} \tau_{t-1}^{U}+\omega_{U}^{S J C}+\gamma_{U}^{S J C} \frac{1}{10} \sum_{i=1}^{10}\left|x_{t-i}-y_{t-i}\right|\right) \\
& \tau_{t}^{L}=\prod\left(\beta_{L}^{S J C} \tau_{t-1}^{L}+\omega_{L}^{S J C}+\gamma_{L}^{S J C} \frac{1}{10} \sum_{i=1}^{10}\left|x_{t-i}-y_{t-i}\right|\right)
\end{aligned}
$$

By using Spearman Contagion Indexes (SCI) and SJC copula, we can only show the existence of contagion effect according to the nature of markets. This method ignores the fact that contagion can appear different from one crisis to another. It does not offer the possibility to distinguish contagion effects of the subprime crisis from those of the European debt crisis. In reality, contagion effect between two or more markets can change in accordance with shocks.

As the main objective of this paper is to prove temporal and spatial asymmetries of unidirectional dependence between financial markets, we estimate a dynamic Gaussian copula. This method enables us to distinguish the contagion effect, if it exists, of every crisis separately. Then, we evaluate the dynamic tail dependences to detect the behavior of dependence. From this, the dynamic Gaussian copula is defined.

\subsubsection{Dynamic Gaussian copula}

$$
C_{t}^{G}\left(x_{t}, y_{t} \mid \rho_{t}\right)=\frac{1}{\sqrt{1-\rho_{t}}} \exp \left\{\frac{2 \rho_{t} x_{t} y_{t}-x_{t}^{2}-y_{t}^{2}}{2\left(1-\rho_{t}^{2}\right)}+\frac{x_{t}^{2}-y_{t}^{2}}{2}\right\}
$$

Dynamic dependence using the Gaussian copula: 


$$
\rho_{t}=\Lambda\left(\beta_{\rho} \rho_{t-1}+\omega_{\rho}+\gamma_{\rho} \frac{1}{10} \sum_{i=1}^{10}\left|x_{t-i}-y_{t-i}\right|\right)
$$

At this stage, the contagion effect is tested using analysis of the structure of time with varying bilateral conditional dependence between financial markets. As such, Gaussian dynamic dependencies are analyzed. Moreover, the multiple breakpoints test is used in both levels of the trend function of every conditional dynamic dependence measure (Claeys \& Vašíček, 2014). The break dates are estimated via the test procedure proposed by CarrionI-Silvestre et al. (2009) coupled with the dynamic programming algorithm of Bai and Perron (2003). The Bai and Perron (2003) structural breakpoints test is efficient (Tam, 2014). It can detect several more breaks than older methods (Xiong et al., 2016). Finally, the level of dependence for each period is compared. The increase in the level of dependence refers to the timing of the contagion effect. We can therefore conclude that spatio-temporal asymmetry of contagion effect is present when the level of contagion varies over time.

\subsection{Sample}

The data is obtained from the Datastream database. In order to compute asymmetric spatial contagion between mature and immature financial markets, G10 and BRICS countries were chosen, and the relationship between the following daily indexes were analyzed: AEX (Netherlands), SMI (Switzerland), OMXS (Sweden), SBF120 (France), FTSEMIB (Italy), Bel20 (Belgium), Fifty50 (India), S\&P500 (U.S.), MDax (Germany), FTSE100 (U.K.), Nikkei250 (Japan), MSCN (China), SPTSX (Canada), RTS (Russia), Bovespa (Brazil) and FTSE South Africa (South Africa). The dataset refers to the period ranging between January 1, 2001 to May 31, 2018 (which includes both the global subprime crisis and European debt crisis).

\section{Results and discussion}

Table 1 reports the principal descriptive statistics of daily log-returns. This table exhibits the presence of non-normality, autocorrelation and heteroscedasticity (ARCH effect) for every single stock market return. According to Durante et al. (2014), determination of conditional dependence can be wrong when heteroscedastic and autocorrelation effects are not eliminated from basic stock market returns. So, the ARMA-GARCH model is used to filter returns before estimating conditional copulas. ${ }^{4}$

As a first objective of the empirical evidence, the three different types of bilateral relationships between the sample markets are analyzed: mature-mature, immature-immature and mature-immature. Focus is particularly on the asymmetry of dependence between markets using conditional static and dynamic copulas coupled with the breakpoints test to demonstrate the existence of spatial and temporal asymmetry of dependencies.

This two-step methodology is based on:

- The asymmetric bilateral relationships set out by Durante and Foscolo (2013).

\footnotetext{
4 The results of the ARMA-GARCH estimations are not detailed here as they are not part of the interpretations, and this allows us to respect the page limitation. But they are available on request to the authors.
} 


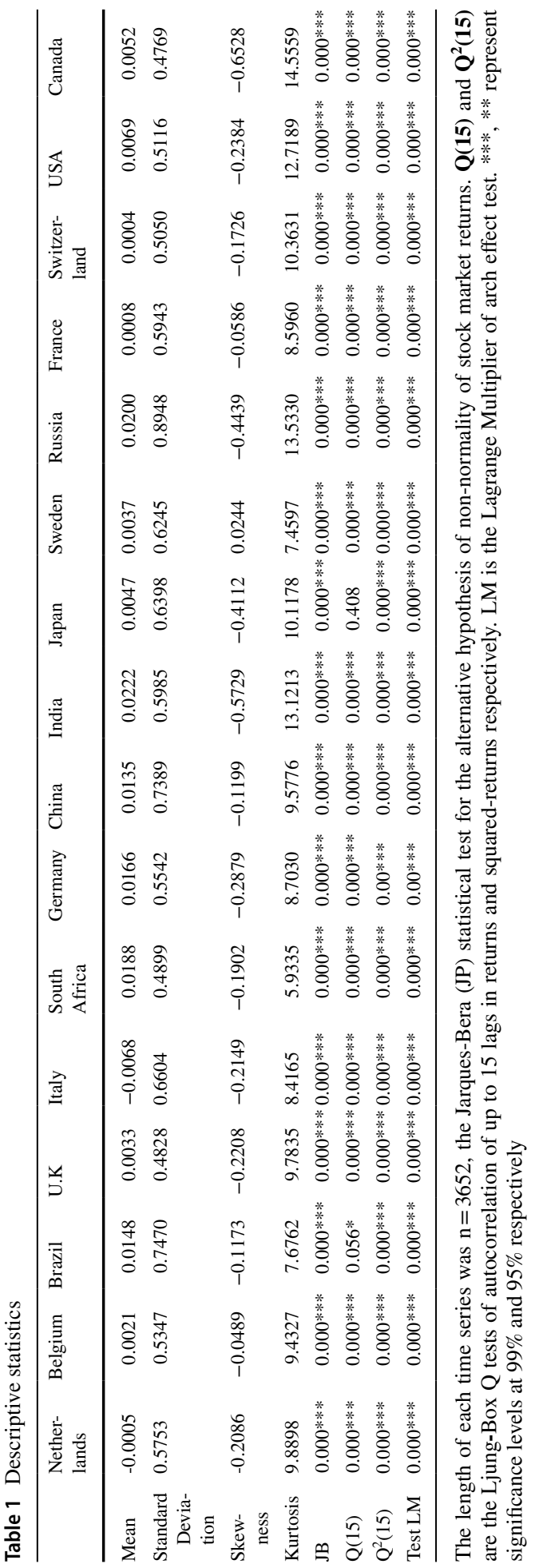


- A temporal analysis of asymmetric dynamic dependence structures. Inspired by the asymmetric computation proposed by Durante et al. (2014), where they suggest for the first time the idea of asymmetric contagion, a novel approach based on the conditional empirical cumulative distribution function $\mathrm{F}(\mathrm{X} / \mathrm{Y})$ is presented.

To begin the analysis, the interest of analyzing the nature of unidirectional bilateral relationships between financial markets using the granger causality test is substantiated. This test helps to justify the hypothesis of the existence of dependencies between markets with different degrees of maturity. In Table 2, this preliminary test confirms the existence of bilateral causality between the markets of the sample with the presence of a spatial asymmetry of relationships even where maturity degrees differ. It also proves the difference between the contagion effect from market A to market B and that of market B to market $\mathrm{A}$ (2005a; Bradley \& Taqqu, 2004, 2005b). This confirms the presence of spatial asymmetry of contagion due to the weight of domestic markets on the international economy (Gjika \& Horváth, 2013).

Following the methodology presented in the previous section, this research first estimated the unidirectional conditional Spearman contagion indexes. This approach is based on comparing the non-parametric copula computed between the central set to the lower tails of the distribution, and the methodology is inspired by the works of Durante and Foscolo (2013). Then, Durante et al. (2014) propose to study the direction of contagion by using different values of $\alpha .^{5}$

The main goal of this first part is to show the presence of spatial asymmetry of contagion between financial markets in addition to the temporal asymmetry ${ }^{6}$ of dependence. Asymmetric contagion indexes provide new information about the unidirectional contagion from one market to another during stress periods (Durante et al., 2014). The spatial asymmetry of financial contagion is verified following the conditional contagion index according to Spearman's correlation coefficients. This index was calculated using the conditional empirical distribution function $\mathrm{F}(\mathrm{X} / \mathrm{Y})$ of filtrated returns, to obtain a conditional threshold copula (X, Y).

Table 3 presents spatial asymmetry of contagion between the sample markets. Finding a high degree of asymmetry mainly for heterogeneous country couples demonstrates the difference between contagion effects sent and received for most countries included in the sample. Moreover, all null values highlight the absence of unidirectional contagion effect from the market of the first column to the market of the first line. Furthermore, an absence of contagion effects from Germany to Italy, Belgium to Switzerland, and between South Africa and Brazil, etc. were found. In addition to this, a symmetric pure contagion relationship which is stronger between mature stock markets than between immature markets was found, in particular for 'Italy-France, Germany-U.K., US-U.K., China-South Africa' country couples. However, we can observe an absence of contagion effect from the U.S. to some other mature markets in the sample, such as Sweden, Switzerland, Germany and Japan. This approach enables us to quantify the difference between the effect of the first market on the second market, and the effect of the second market on the first. Then, we find

\footnotetext{
5 See the Methodology section.

6 Temporal asymmetry refers to the difference of the level of dependence during growth, in both normal and stress periods. This proves the presence of contagion when dependence increases during stress periods in comparison with normal periods. The next part of this paper discusses temporal asymmetry of contagion when contagion effects differ from one crisis to another.
} 


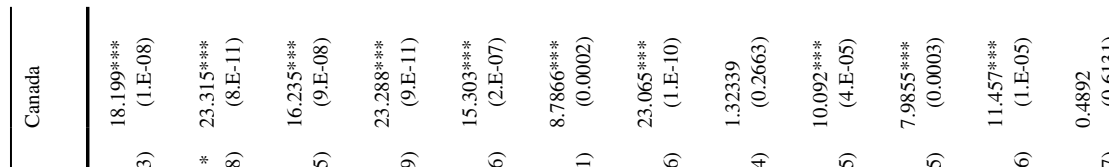

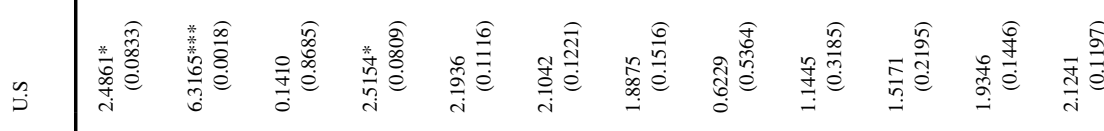

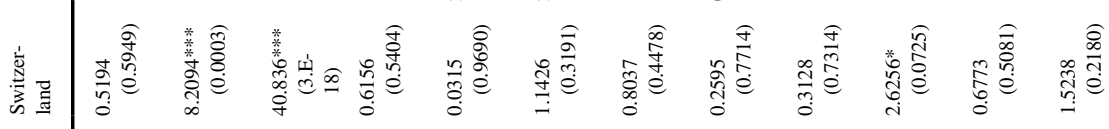

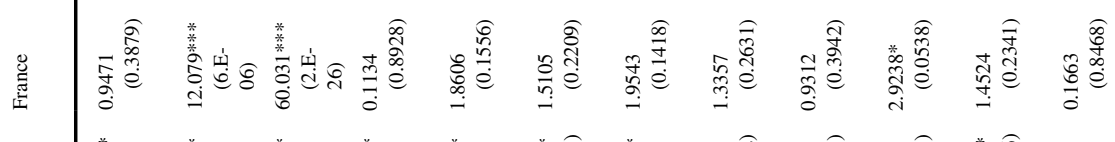

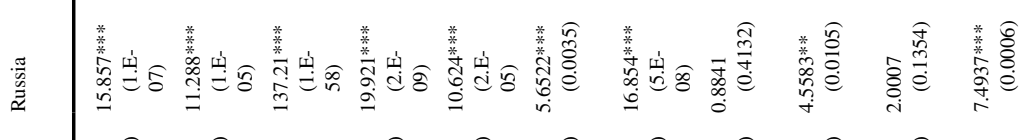

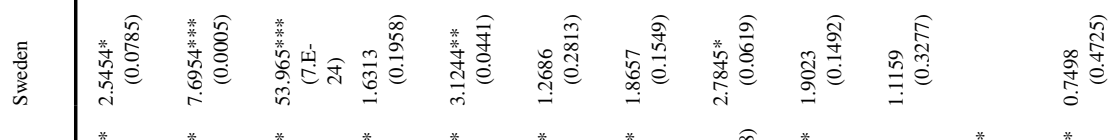

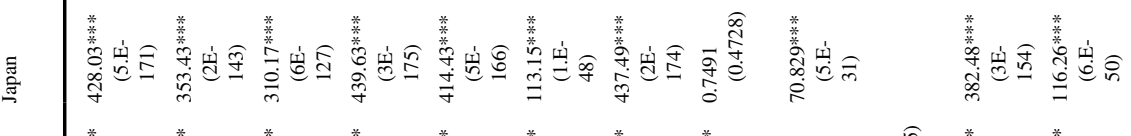

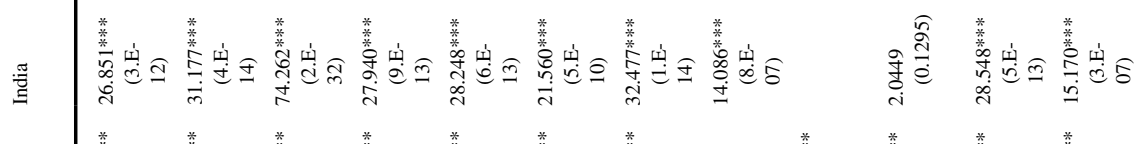

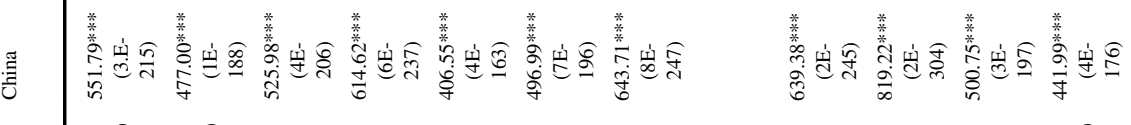

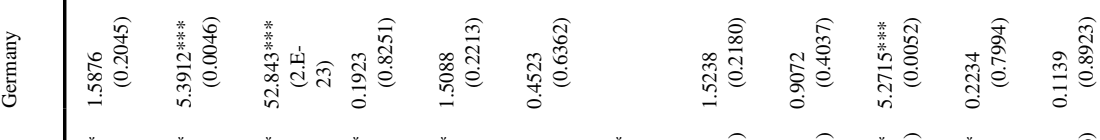

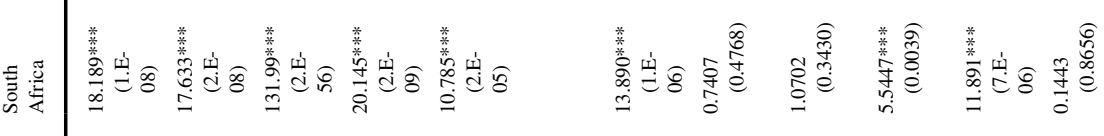

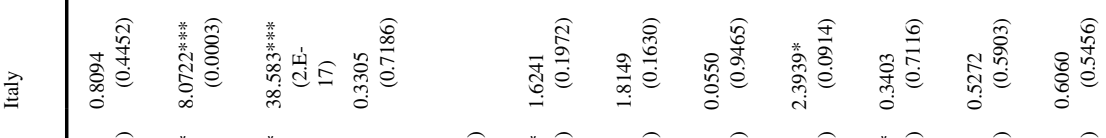

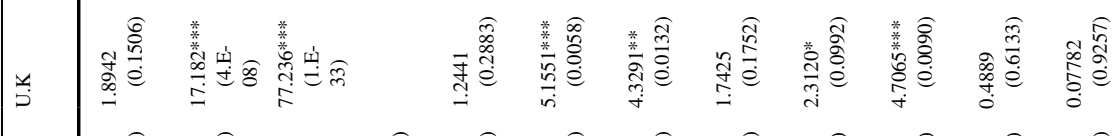

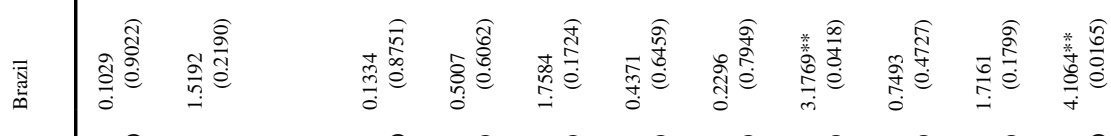

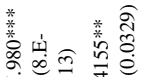

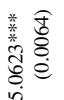

旁㝵

总

赵害

蓉

ㄱำ

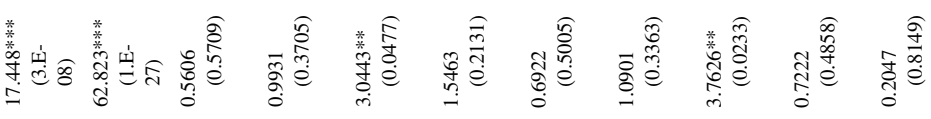

童

离 m.

|

竞高

音

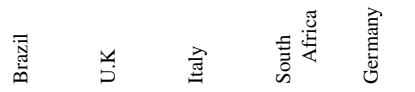

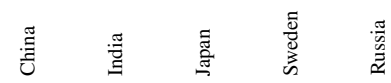




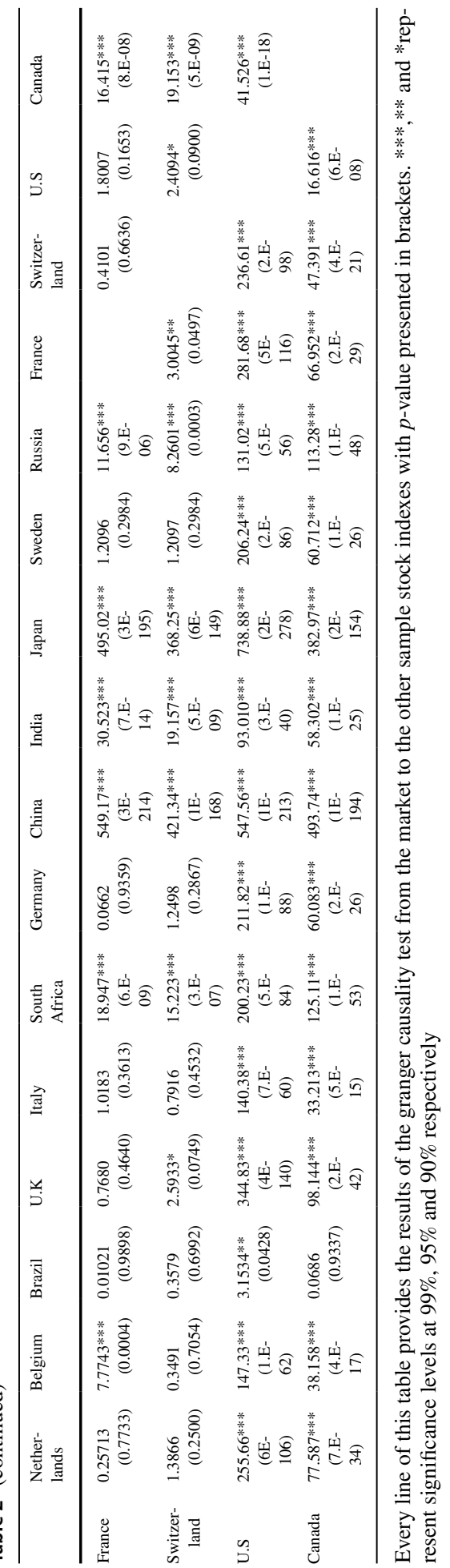




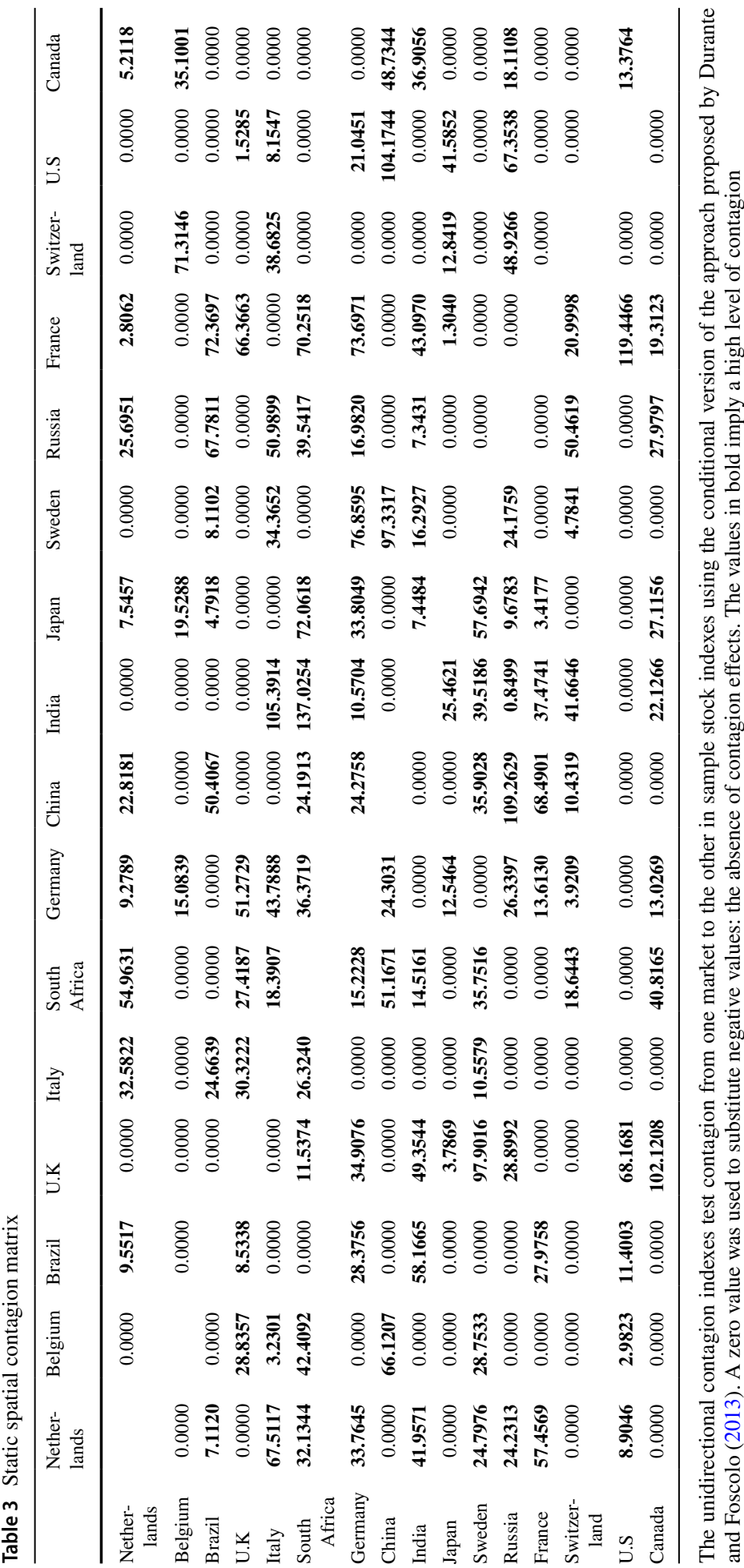


a spatial asymmetry for contagion effects between immature market couples such as South Africa-Russia, Brazil-China, Russia-Brazil, India-Russia, and China-Russia. Spatial asymmetry is also present for mature country couples such as U.K.-Belgium, Japan-Netherlands and U.S.-Canada.

Table 3 demonstrates the existence of symmetric contagion effects between some European and Asian financial markets such as between Germany-Japan, France-Japan, SwedenIndia, France-India, China-Sweden and China-Germany. This result supports the findings of Zhou et al. (2018) but contradicts these of Zorgati et al. (2020), who state that the spatial contagion is limited for countries that are geographically distant.

However, the present aim is to test the existence of pure contagion effects. Here, the absence of contagion effect between mature and immature markets highlights how the channels of contagion depend on fundamentals such as trade relationships, exchange rate, etc.

The high level of the contagion index from the U.S. to the U.K. shows the presence of pure contagion effect received by the U.K. market, during the global financial crisis and European debt crisis, due to the role of investor behavior in the crisis transmission mechanism (Engle, 2009). With a focus on heterogeneous country couples, these estimations indicate the absence of contagion effect from U.S. to immature markets except for Brazil, this being due to the vulnerability of the Brazilian financial market. Spatial asymmetry for mature-immature country couples such as China-Netherlands, U.K.-India and U.S.-Brazil were also identified.

The SJC Copula, which compares the dynamic dependence level between the lower and upper tails of the distribution, confirms the result on the increase of dependence during stress periods in comparison with calm periods.

Table 4 provides the results of upper and lower dependence levels using the SJC copula. This study focuses on the SJC dynamic copula because it takes into account the asymmetry between lower and upper tail dependencies in comparison with Student and Gumbel copula (Filho et al., 2014; Wen et al., 2012). Student and Gumbel copulas are also interested in the lower and upper tail dependencies based on the hypotheses of symmetry of dependence in extreme periods, even where dependencies for lower and upper tails are the same.

In this step, the timing of the presence of contagion effects is investigated by analyzing the conditional dynamic dependence. Furthermore, each crisis has specific characteristics, suggesting that the contagion effect changes from one crisis to another (over time). To identify the contagion effect for every crisis separately, the second part of this study begins by estimating the conditional dynamic Gaussian copula. This is calculated from the conditional empirical distribution function which is used to calculate the dynamic unidirectional dependencies. Here, the conditional dynamic Gaussian copula takes into account the whole distribution of the data (Wen et al., 2012).

This table reveals the expansion of the level of dependence during the stress period in comparison with the calm periods for most of the country couples of this sample. It also highlights the particularity of the Chinese market. No tail dependencies were sent or received to or from any markets of this sample. This result, obtained using more robust methods, supports the findings of Shen et al. (2015) regarding the independence of the Chinese financial market from other financial markets even in times of crisis. This phenomenon can be explained by the limited influence of European economic and financial conditions on Chinese investors.

For the second part of the estimations, unidirectional dependence levels were calculated using conditional dynamic Gaussian copulas. In Table 5, the results display high levels of dependencies between all mature markets except Japan. Moreover, several precise 


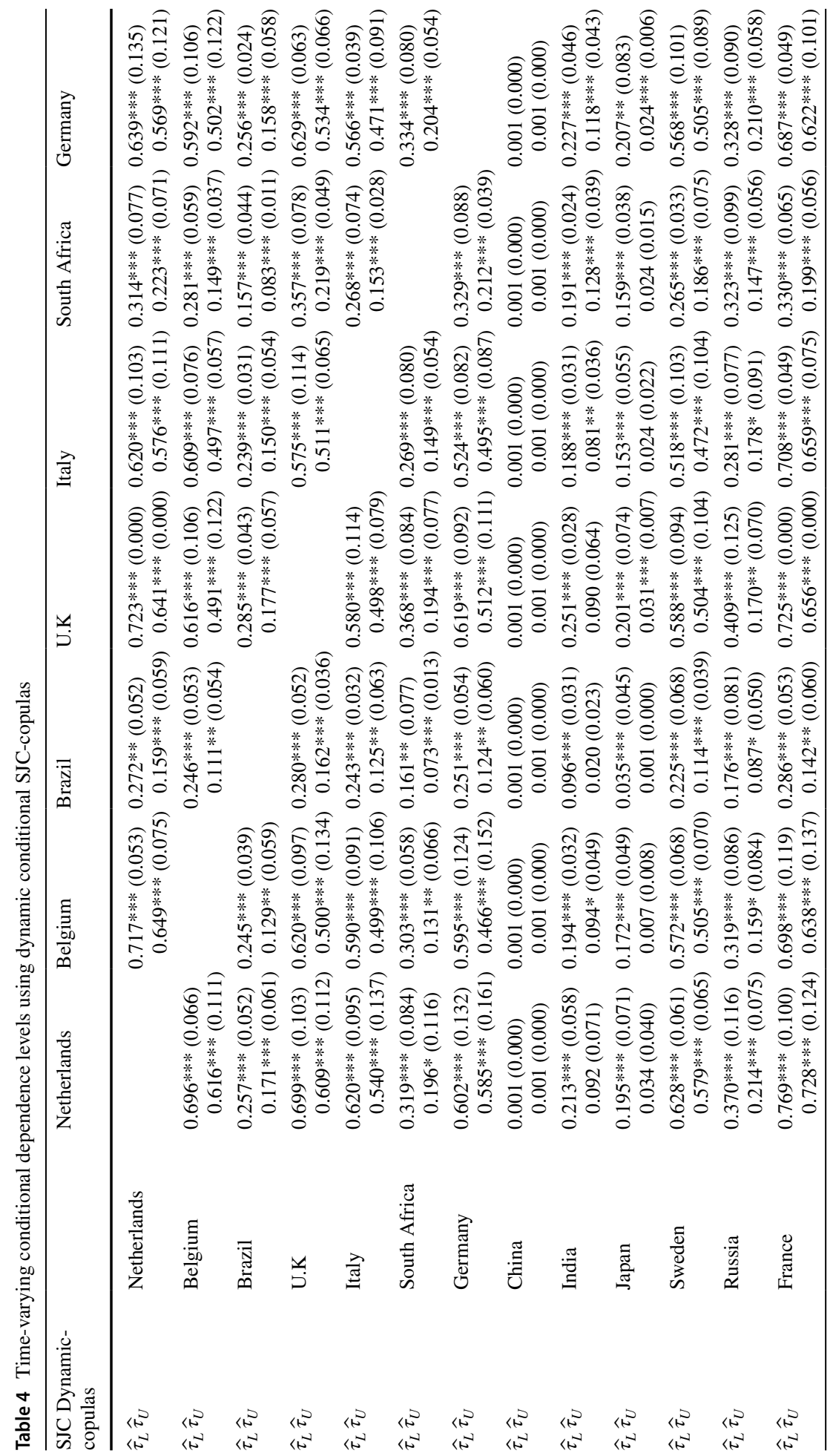




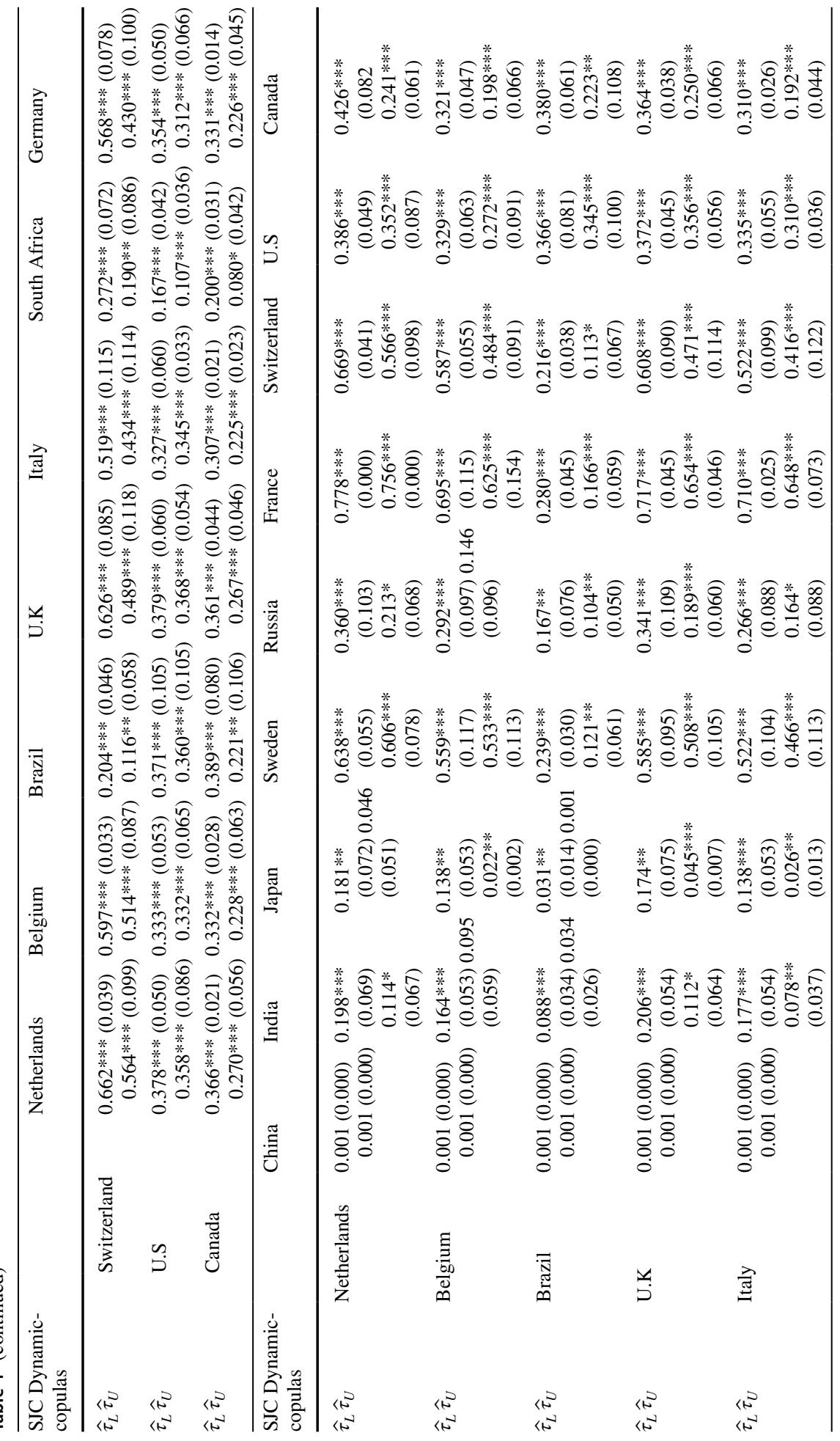




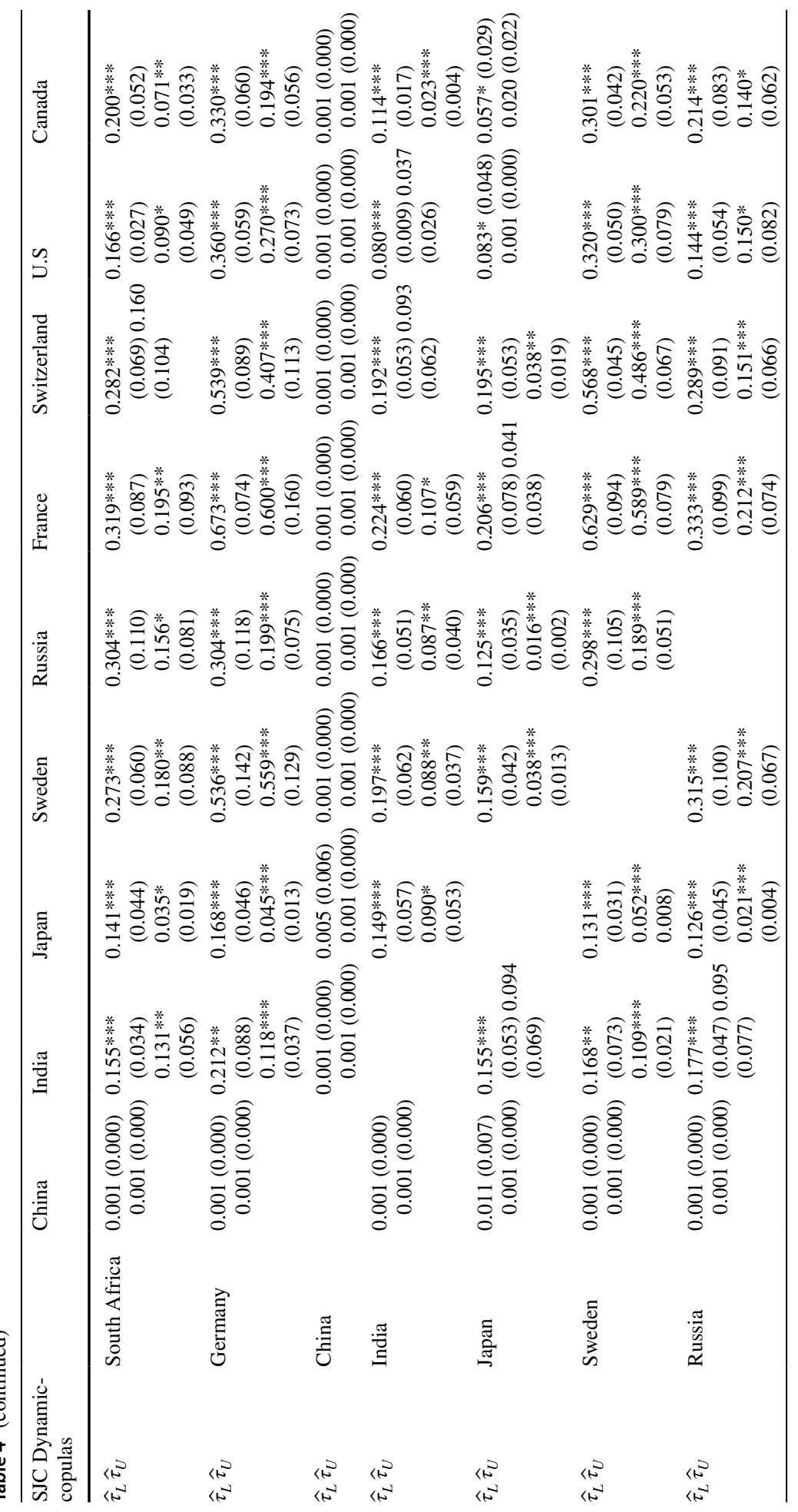




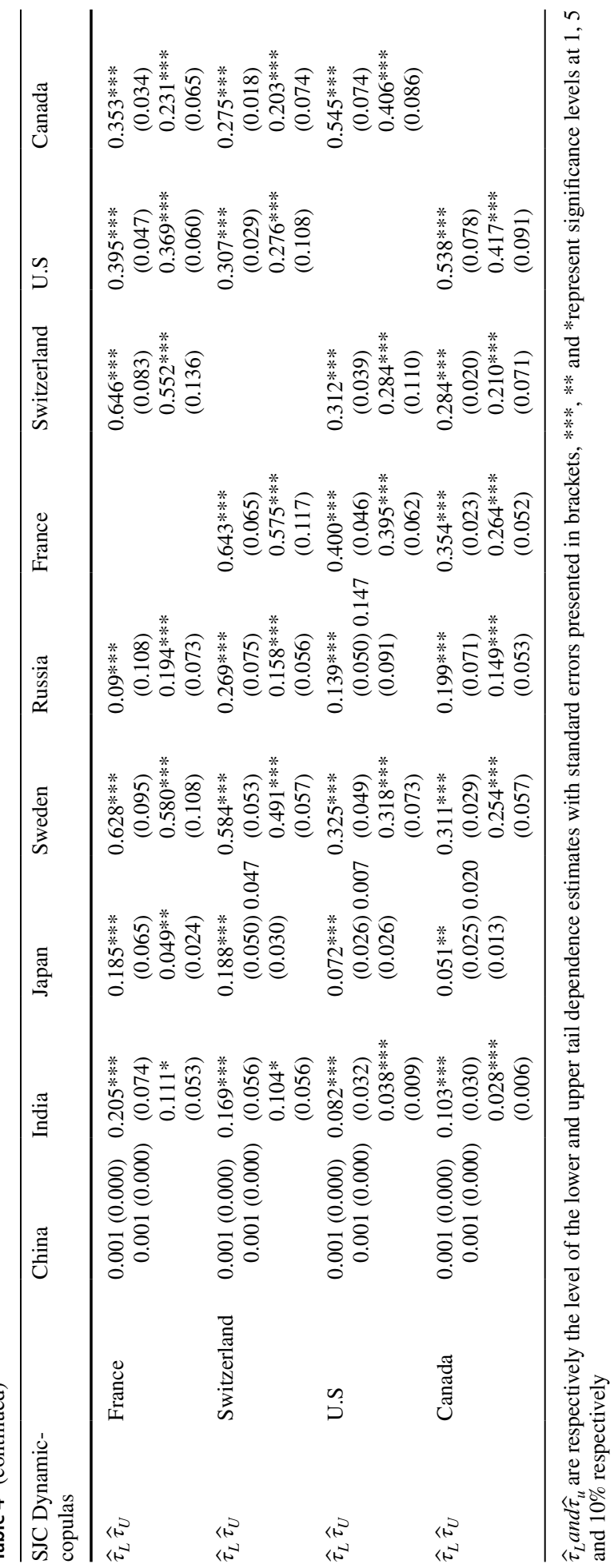




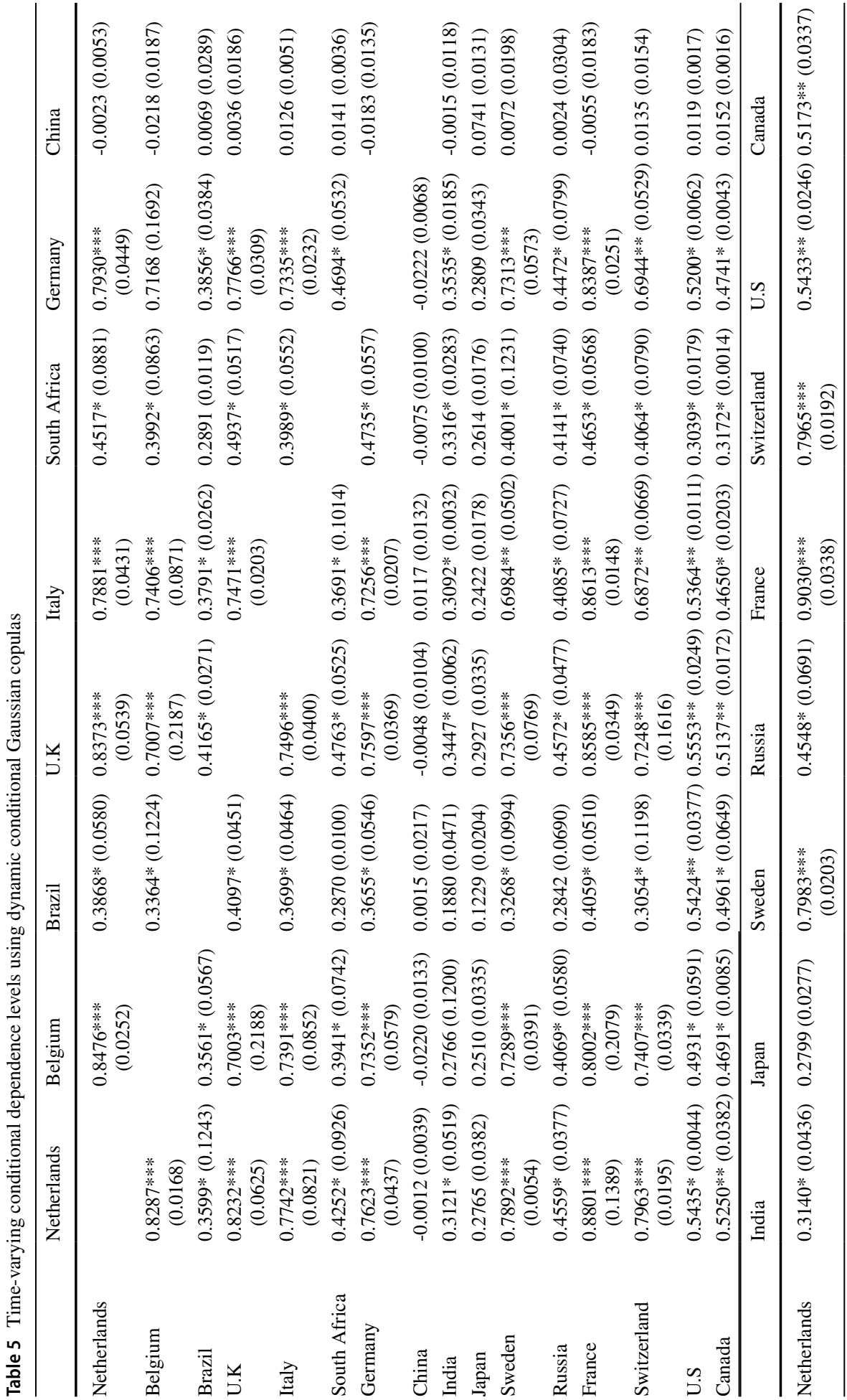




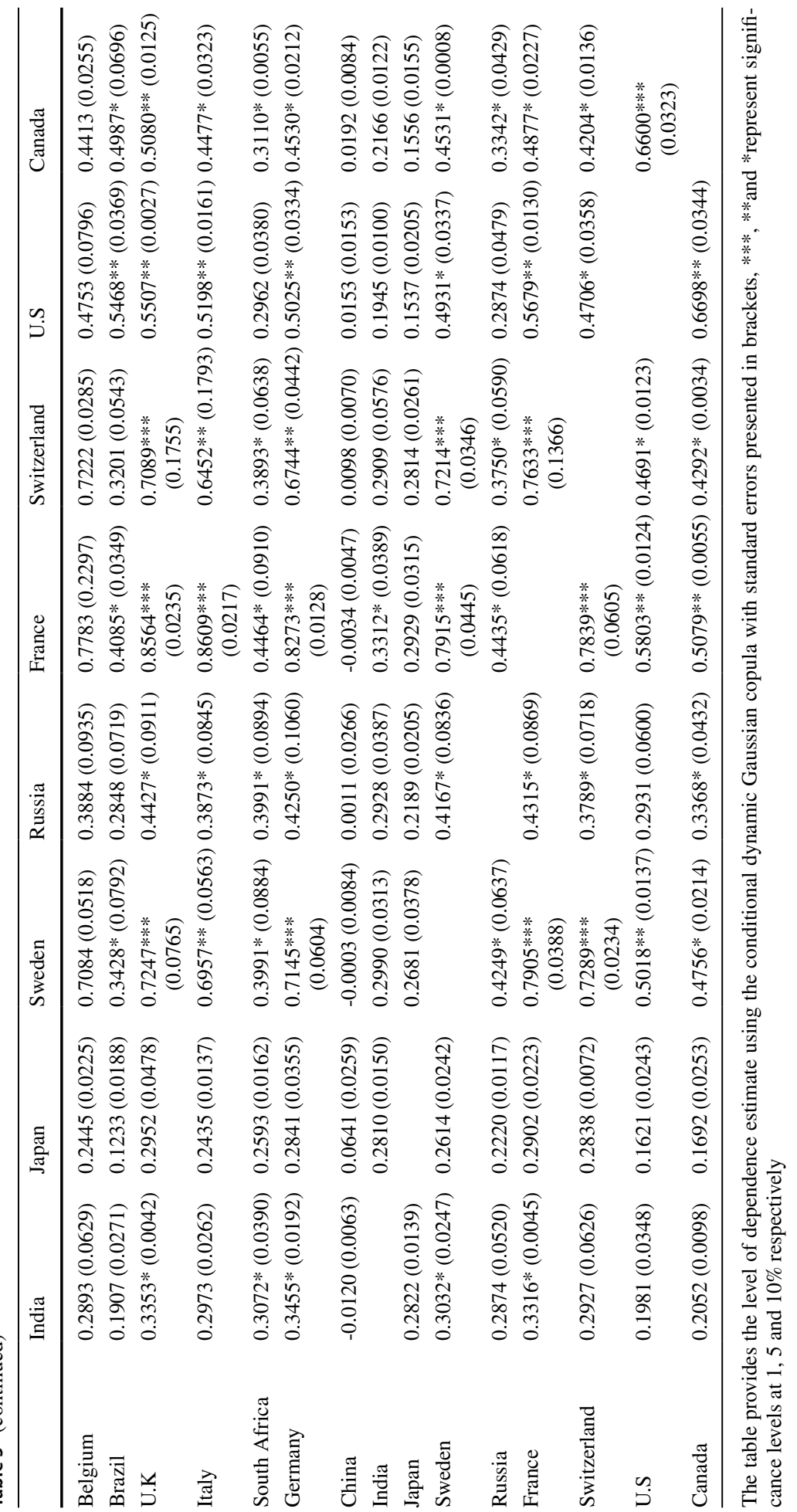




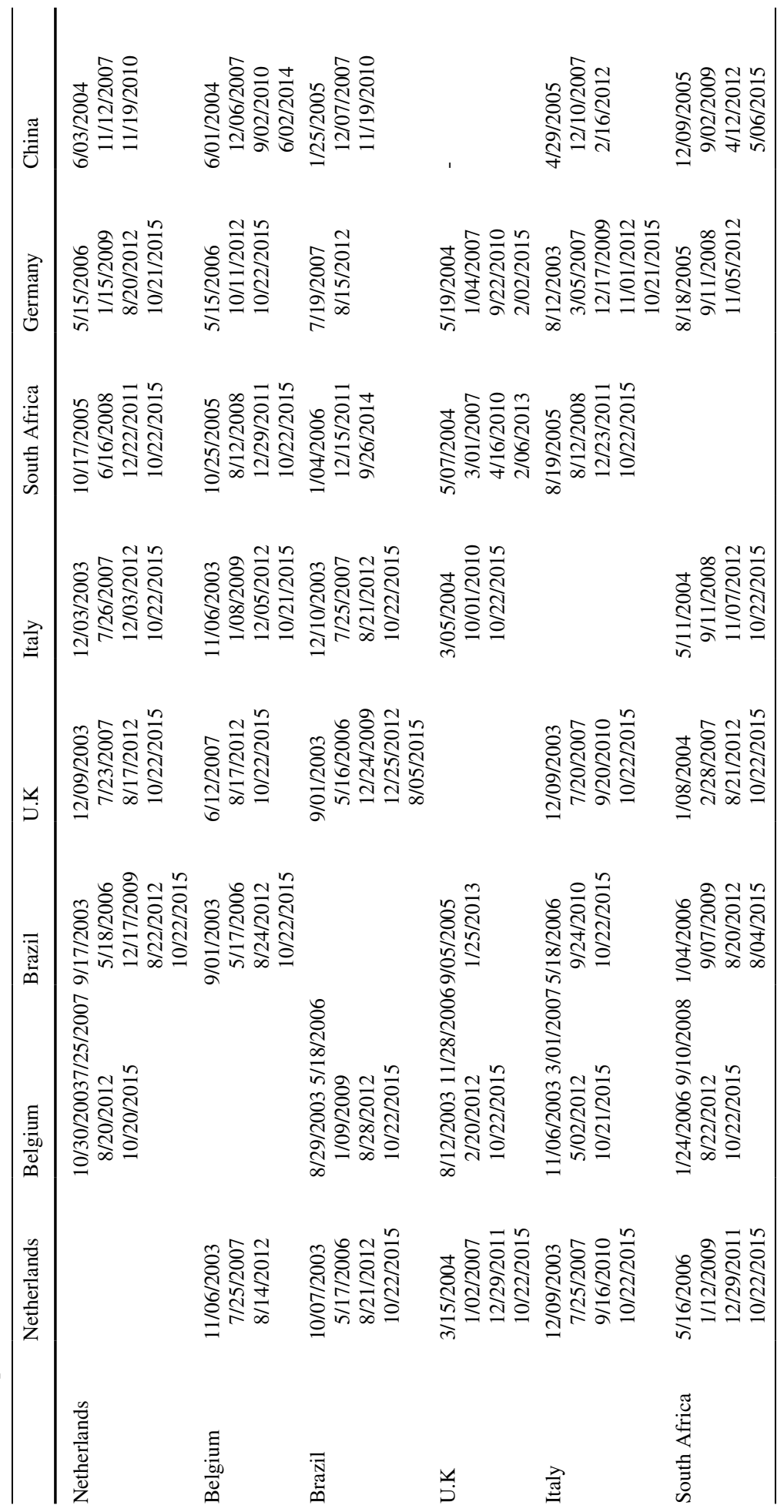




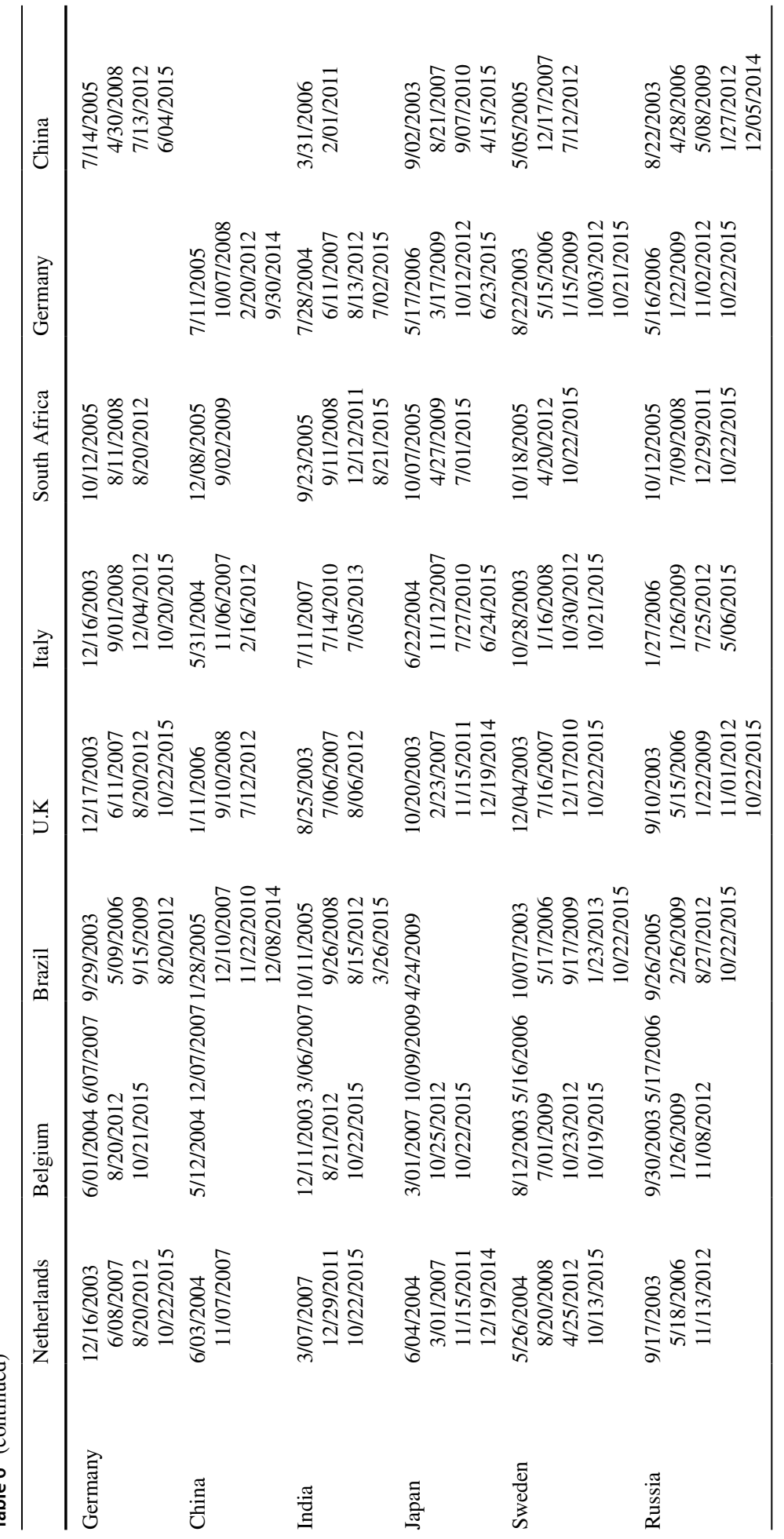




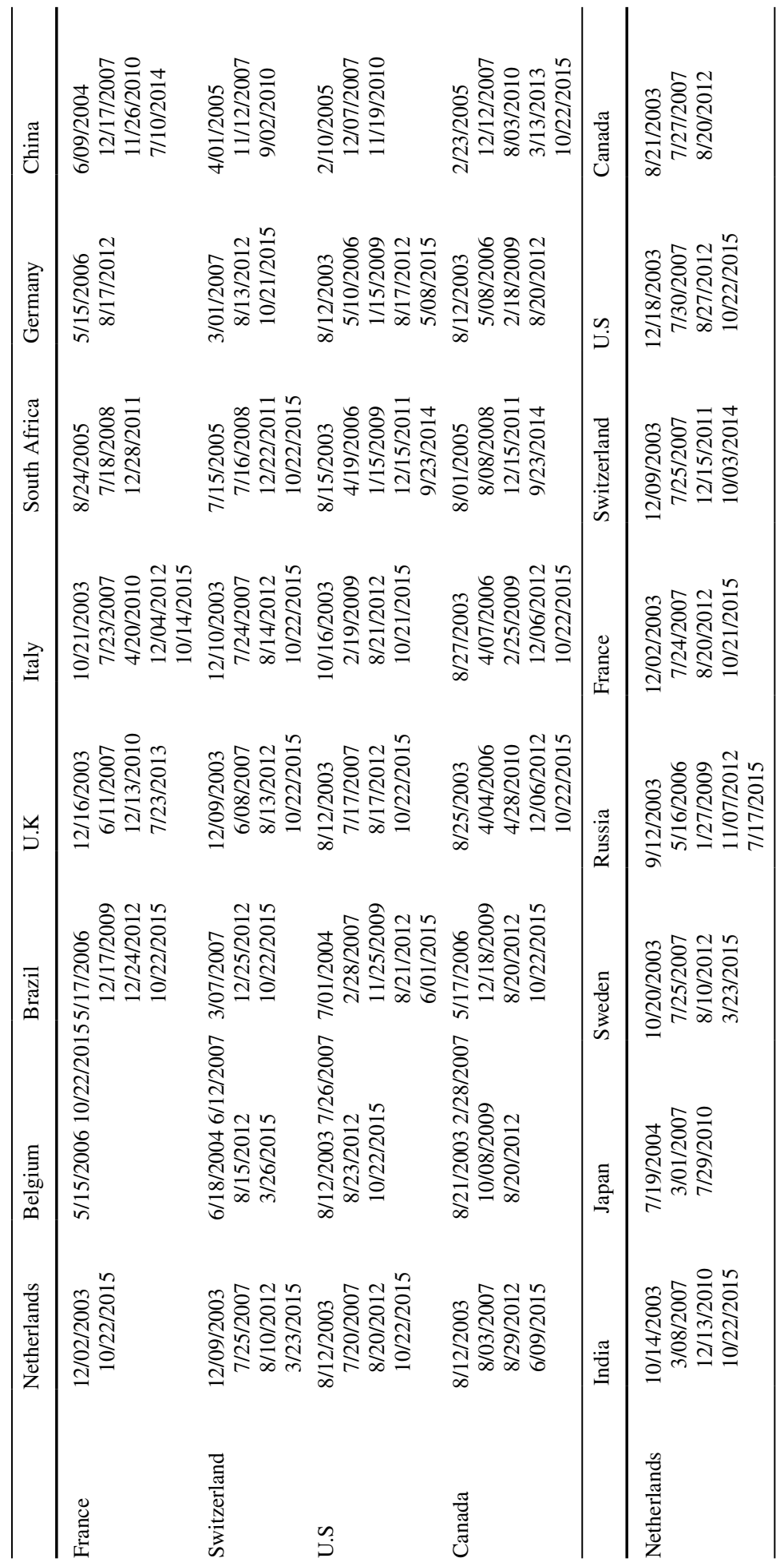




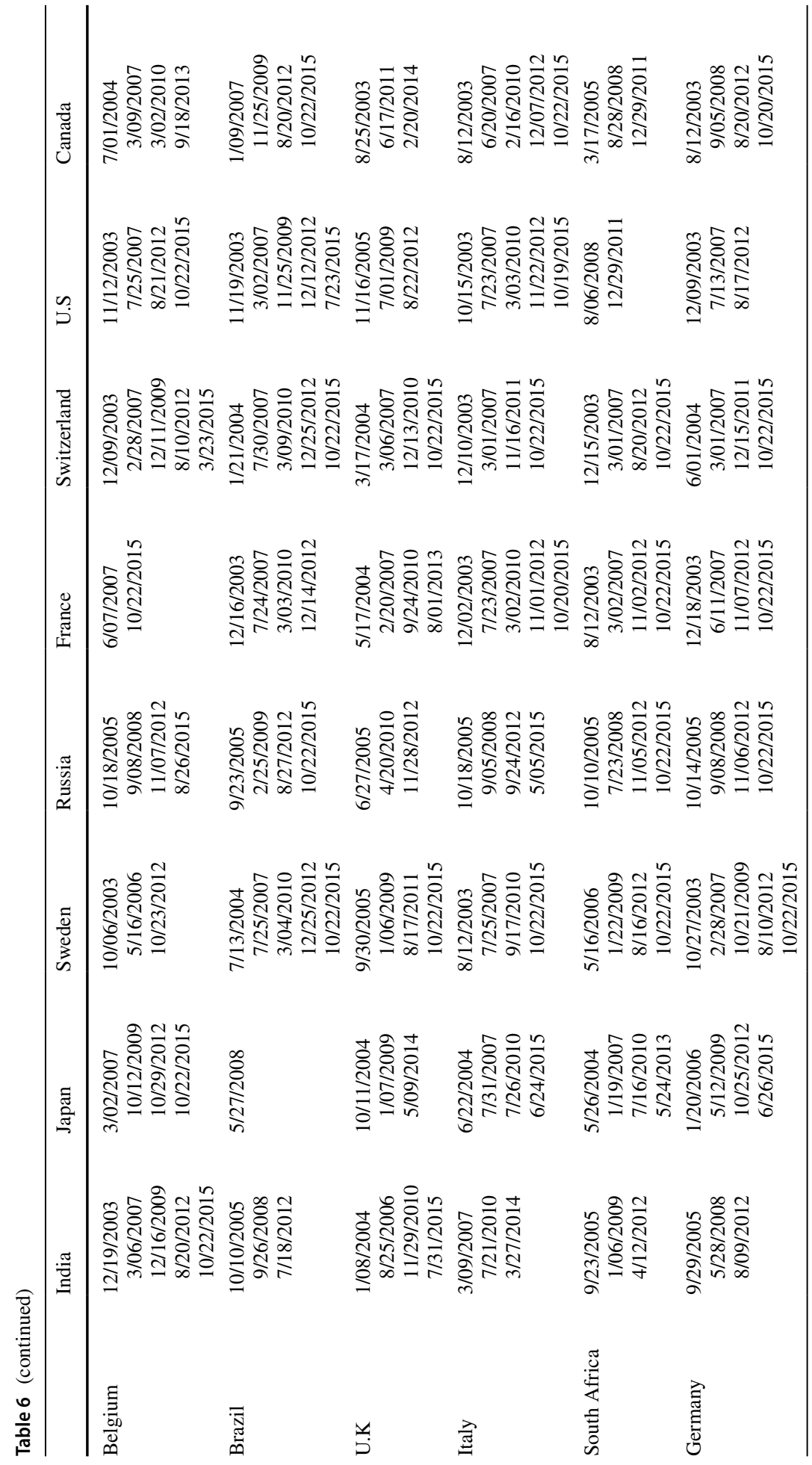




\begin{tabular}{|c|c|c|c|c|c|}
\hline 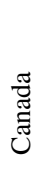 & 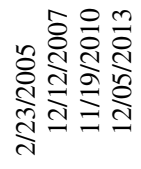 & 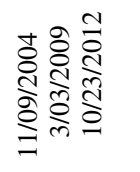 & $\begin{array}{l}\stackrel{m}{\stackrel{m}{I}} \\
\stackrel{m}{=}\end{array}$ & 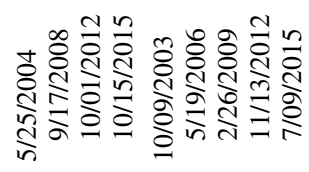 & 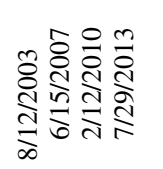 \\
\hline$\stackrel{\sim}{\sigma}$ & 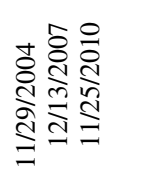 & 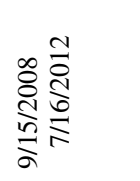 & 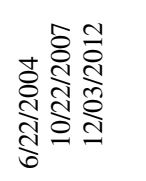 & 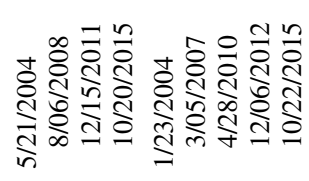 & 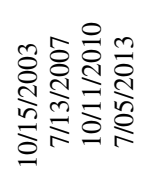 \\
\hline 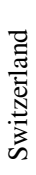 & 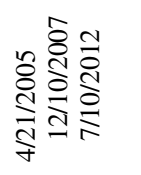 & 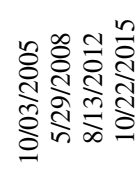 & 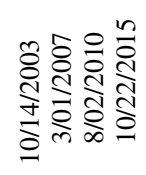 & 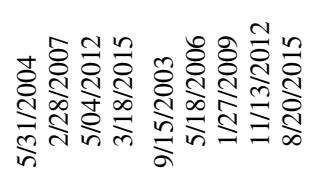 & 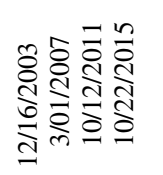 \\
\hline 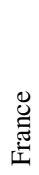 & 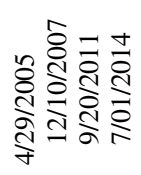 & 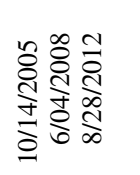 & 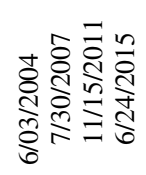 & 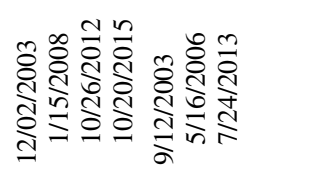 & \\
\hline 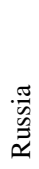 & 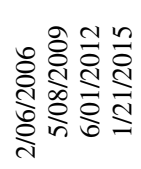 & 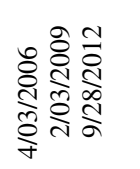 & 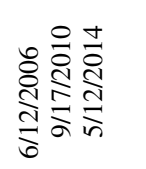 & 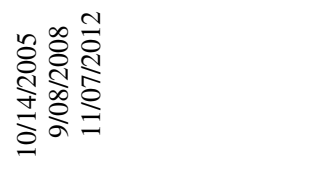 & 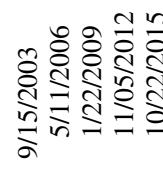 \\
\hline & 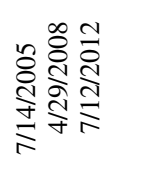 & 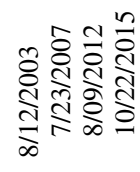 & 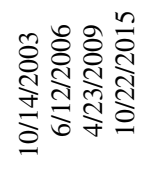 & 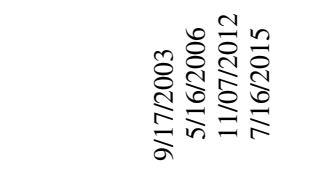 & 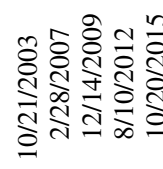 \\
\hline $\begin{array}{l}\text { : } \\
\text { :్ }\end{array}$ & 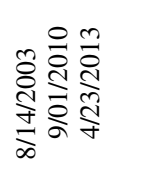 & 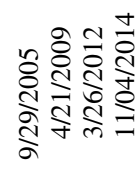 & & 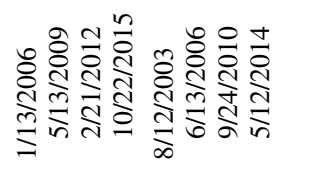 & 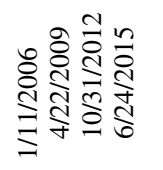 \\
\hline : & 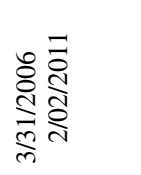 & & 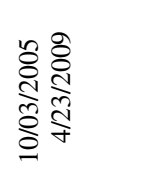 & 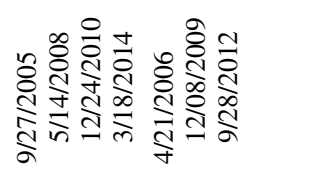 & 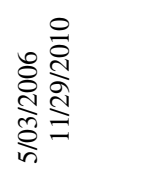 \\
\hline & 章 & 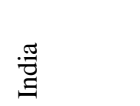 & $\begin{array}{l}\text { 胥 } \\
\text { 窵 }\end{array}$ & 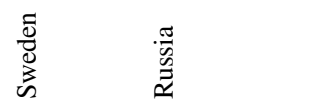 & 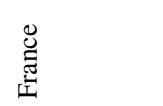 \\
\hline
\end{tabular}




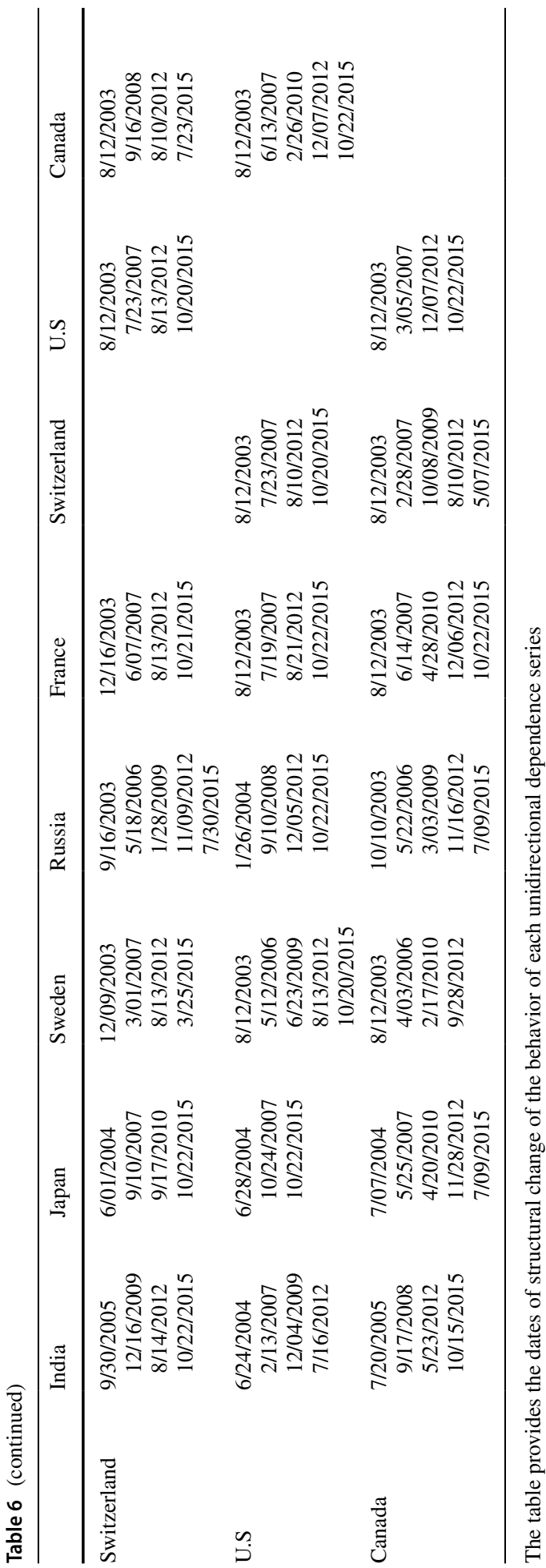


Table 7 Features of one-directional dependence by period

\begin{tabular}{|c|c|c|c|c|c|c|c|c|c|c|c|c|c|c|c|c|}
\hline & $\begin{array}{l}\text { Nether- } \\
\text { lands }\end{array}$ & elgium & Brazil & U.K. & Italy & $\begin{array}{l}\text { South } \\
\text { Africa }\end{array}$ & Germany & China & India & Japan & Sweden & Russia & France & $\begin{array}{l}\text { Switzer- } \\
\text { land }\end{array}$ & U.S. & Canada \\
\hline $\begin{array}{l}\text { Nether- } \\
\text { lands }\end{array}$ & & $\begin{array}{c}0.8481 \\
(0 . .0008) \\
0.8342 \\
(0 . .0007) \\
0 . .8625 \\
(0.0006) \\
0.8451 \\
(0.0008) \\
0.8406 \\
(0.0009)\end{array}$ & $\begin{array}{c}0.3899 \\
(0.0018) \\
0.3635 \\
(0.0018) \\
\mathbf{0 . 4 2 9 1} \\
(\mathbf{0 . 0 0 1 6 )} \\
0.4130 \\
(0.0018) \\
0.3784 \\
(0.0017) \\
0.3328 \\
(0.0019)\end{array}$ & $\begin{array}{c}0.8516 \\
(0.0017) \\
0.8235 \\
(0.0015) \\
\mathbf{0 . 8 6 6 8} \\
\mathbf{( 0 . 0 0 1 3 )} \\
0.8336 \\
(0.0016) \\
0.7875 \\
(0.0018)\end{array}$ & $\begin{array}{c}0.8009 \\
(0.0014) \\
0.7693 \\
(0.0012) \\
\mathbf{0 . 8 0 9 2} \\
(\mathbf{0 . 0 0 1 0 )} \\
0.7912 \\
(0.014) \\
0.7537 \\
(0.0015)\end{array}$ & $\begin{array}{c}0.4078 \\
(0.0022) \\
\mathbf{0 . 4 8 7 0} \\
(\mathbf{0 . 0 0 3 0 )} \\
\mathbf{0 . 5 0 3 6} \\
(\mathbf{0 . 0 0 2 6 )} \\
0.4650 \\
(0.0025) \\
0.4065 \\
(0.0030)\end{array}$ & $\begin{array}{c}0.7781 \\
(0.0010) \\
\mathbf{0 . 8 1 4 4} \\
(\mathbf{0 . 0 0 1 5 )} \\
0.8247 \\
(0.0013) \\
0.7925 \\
(0.0013) \\
0.7591 \\
(0.0015)\end{array}$ & $\begin{array}{c}-0.0019 \\
(0.0002) \\
-0.0037 \\
(0.0002) \\
-0.0011 \\
(0.0002) \\
-0.0023 \\
(0.0001)\end{array}$ & $\begin{array}{c}0.2922 \\
(0.0013) \\
0.3130 \\
(0.0012) \\
\mathbf{0 . 3 5 1 7} \\
(\mathbf{0 . 0 0 1 2 )} \\
0.3173 \\
(0.0010) \\
0.2778 \\
(0.0014)\end{array}$ & $\begin{array}{c}0.2771 \\
(0.0009) \\
0.2837 \\
(0.0010) \\
0.2692 \\
(0.0009) \\
0.2845 \\
(0.0006)\end{array}$ & $\begin{array}{c}0.7903 \\
(0.0007) \\
0.8056 \\
(0.0006) \\
0.7899 \\
(0.0005) \\
0.8075 \\
(0.0007) \\
0.8023 \\
(0.0007)\end{array}$ & $\begin{array}{c}0.4489 \\
(0.0023) \\
0.3973 \\
(0.0023) \\
\mathbf{0 . 4 7 1 2} \\
(\mathbf{0 . 0 0 2 3 )}) \\
\mathbf{0 . 5 0 5 4} \\
\mathbf{( 0 . 0 0 1 9 )} \\
0.4306 \\
(0.0023) \\
0.4548 \\
(0.0022) \\
\end{array}$ & $\begin{array}{c}0.9174 \\
(0.0011) \\
0.8925 \\
(0.0010) \\
0.9192 \\
(0.0008) \\
0.9015 \\
(0.0010) \\
0.8717 \\
(0.0011) \\
\end{array}$ & $\begin{array}{c}0.8036 \\
(0.0007) \\
0.7890 \\
(0.0006) \\
0.8045 \\
(0.0005) \\
0.7888 \\
(0.0007) \\
0.7945 \\
(0.0006)\end{array}$ & $\begin{array}{c}0.5474 \\
(0.0008) \\
0.5360 \\
(0.0007) \\
0.5569 \\
(0.0006) \\
0.5433 \\
(0.0008) \\
0.5225 \\
(0.0008)\end{array}$ & $\begin{array}{c}0.5111 \\
(0.0012) \\
0.5305 \\
(0.0010) \\
0.5012 \\
(0.0009) \\
0.5251 \\
(0.0008)\end{array}$ \\
\hline Belgium & $\begin{array}{c}0.8335 \\
(0.0006) \\
0.8214 \\
(0.0005) \\
0.8346 \\
(0.0004) \\
0.8260 \\
(0.0004)\end{array}$ & & $\begin{array}{c}0.3366 \\
(0.0039) \\
0.3147 \\
(0.0039) \\
\mathbf{0 . 3 9 8 1} \\
(\mathbf{0 . 0 0 2 5 )} \\
0.3472 \\
(0.0036) \\
0.1969 \\
(0.0039)\end{array}$ & $\begin{array}{c}0.7132 \\
(0.0046) \\
\mathbf{0 . 7 8 8 1} \\
\mathbf{( 0 . 0 0 5 1 )} \\
0.7385 \\
(0.0066) \\
0.4502 \\
(0.0073)\end{array}$ & $\begin{array}{c}0.7391 \\
(0.0029) \\
0.7227 \\
(0.0021) \\
\mathbf{0 . 7 8 8 5} \\
(\mathbf{0 . 0 0 2 5 )} \\
0.7696 \\
(0.0029) \\
0.6740 \\
(0.0030)\end{array}$ & $\begin{array}{c}0.3631 \\
(0.0021) \\
\mathbf{0 . 4 3 7 5} \\
(\mathbf{0 . 0 0 2 7}) \\
\mathbf{0 . 4 5 3 0} \\
(\mathbf{0 . 0 0 2 5}) \\
0.4215 \\
(0.0023) \\
0.3227 \\
(0.0028)\end{array}$ & $\begin{array}{c}0.6950 \\
(0.0041) \\
\mathbf{0 . 7 8 2 1} \\
(\mathbf{0 . 0 0 3 7 )} \\
0.7485 \\
(0.0054) \\
0.5644 \\
(0.0058)\end{array}$ & $\begin{array}{c}-0.0194 \\
(0.0006) \\
-0.0268 \\
(0.0006) \\
-0.0191 \\
(0.0007) \\
-0.0238 \\
(0.0006) \\
-0.0193 \\
(0.0006)\end{array}$ & $\begin{array}{c}0.2303 \\
(0.0018) \\
\mathbf{0 . 2 9 6 8} \\
(\mathbf{0 . 0 0 1 7 )} \\
\mathbf{0 . 3 4 1 7} \\
(\mathbf{0 . 0 0 1 9 )} \\
0.3231 \\
(0.0019) \\
0.2954 \\
(0.0017) \\
0.2493 \\
(0.0019)\end{array}$ & $\begin{array}{c}0.2478 \\
(0.0005) \\
0.2292 \\
(0.0008) \\
0.2431 \\
(0.0008) \\
0.2467 \\
(0.0008) \\
0.2513 \\
(0.0008)\end{array}$ & $\begin{array}{c}0.6930 \\
(0.0018) \\
0.6840 \\
(0.0019) \\
\mathbf{0 . 7 2 9 1} \\
(\mathbf{0 . 0 0 1 2 )} \\
0.70035 \\
(0.0013)\end{array}$ & $\begin{array}{c}0.3229 \\
(0.0022) \\
\mathbf{0 . 4 0 2 0} \\
(\mathbf{0 . 0 0 2 8 )} \\
\mathbf{0 . 4 6 5 0} \\
(\mathbf{0 . 0 0 2 4 )} \\
0.3717 \\
(0.0029) \\
0.3895 \\
(0.0029)\end{array}$ & \begin{tabular}{|c}
0.7983 \\
$(0.0049)$ \\
$\mathbf{0 . 8 4 3 0}$ \\
$\mathbf{( 0 . 0 0 4 3 )}$ \\
0.5217 \\
$(0.0077)$ \\
\end{tabular} & $\begin{array}{c}0.7265 \\
(0.0010) \\
0.7116 \\
(0.0010) \\
0.7331 \\
(0.0010) \\
0.7261 \\
(0.0010) \\
0.7154 \\
(0.0011) \\
0.7219 \\
(0.0010)\end{array}$ & $\begin{array}{c}0.4760 \\
(0.0025) \\
0.4514 \\
(0.0022) \\
\mathbf{0 . 5 2 2 0} \\
(\mathbf{0 . 0 0 1 9 )} \\
0.4903 \\
(0.0024) \\
0.3992 \\
(0.0026)\end{array}$ & $\begin{array}{c}0.4432 \\
(0.0006) \\
0.4064 \\
(0.0007) \\
\mathbf{0 . 4 6 1 3} \\
(\mathbf{0 . 0 0 0 7 )} \\
0.4550 \\
(0.0006) \\
0.4367 \\
(0.0005)\end{array}$ \\
\hline Brazil & $\begin{array}{c}0.3849 \\
(0.0040) \\
0.3377 \\
(0.0041) \\
\mathbf{0 . 4 1 3 5} \\
(\mathbf{0 . 0 0 2 7 )} \\
0.3592 \\
(0.0038) \\
0.2280 \\
(0.0041)\end{array}$ & $\begin{array}{c}0.3562 \\
(0.0018) \\
0.3296 \\
(0.0017) \\
\mathbf{0 . 3 8 3 2} \\
(\mathbf{0 . 0 0 1 8}) \\
\mathbf{0 . 3 9 9 4} \\
(\mathbf{0 . 0 0 1 5 )} \\
0.3525 \\
(0.0016) \\
0.3014 \\
(0.0018)\end{array}$ & & $\begin{array}{c}0.4173 \\
(0.0008) \\
0.3908 \\
(0.0008) \\
0.4383 \\
(\mathbf{0 . 0 0 0 0 7 )} \\
0.4330 \\
(0.0008) \\
0.4023 \\
(0.0008) \\
0.4077 \\
(0.0008)\end{array}$ & $\begin{array}{c}0.3776 \\
(0.0009) \\
0.3680 \\
(0.0008) \\
\mathbf{0 . 3 9 4 7} \\
(\mathbf{0 . 0 0 0 7 )} \\
0.3756 \\
(0.0008) \\
0.3701 \\
(0.0009)\end{array}$ & $\begin{array}{c}0.2843 \\
(0.0003) \\
0.2933 \\
(0.0003) \\
0.2860 \\
(0.0004) \\
0.2911 \\
(0.0004)\end{array}$ & $\begin{array}{c}0.3777 \\
(0.0009) \\
\mathbf{0 . 4 0 7 7} \\
(\mathbf{0 . 0 0 1 0 )} \\
0.3750 \\
(0.0009)\end{array}$ & $\begin{array}{c}0.0078 \\
(0.0009) \\
-0.0044 \\
(0.0010) \\
0.0158 \\
(0.0010) \\
0.0072 \\
(0.0006)\end{array}$ & $\begin{array}{c}0.1802 \\
(0.0007) \\
0.1942 \\
(0.0009) \\
0.2070 \\
(0.0008) \\
0.1870 \\
(0.0006)\end{array}$ & $\begin{array}{c}0.1217 \\
(0.0004) \\
0.1244 \\
(0.0004)\end{array}$ & $\begin{array}{c}0.3618 \\
(0.0022) \\
0.3140 \\
(0.0024) \\
\mathbf{0 . 4 0 4 9} \\
(\mathbf{0 . 0 0 2 6 )} \\
0.3778 \\
(0.025) \\
0.3236 \\
(0.0025) \\
0.2713 \\
(0.0026)\end{array}$ & $\begin{array}{c}0.2375 \\
(0.0018) \\
\mathbf{0 . 3 0 5 6} \\
(\mathbf{0 . 0 0 2 1 )} \\
\mathbf{0 . 3 2 8 6} \\
(\mathbf{0 . 0 0 2 1 )} \\
0.2946 \\
(0.0022) \\
0.2724 \\
(0.0024)\end{array}$ & \begin{tabular}{|c}
0.4102 \\
$(0.0011)$ \\
0.3929 \\
$(0.0010)$ \\
$\mathbf{0 . 4 3 7 1}$ \\
$(\mathbf{0 . 0 0 1 2 )}$ \\
0.4259 \\
$(0.0011)$ \\
0.3952 \\
$(0.0008)$
\end{tabular} & $\begin{array}{c}0.3361 \\
(0.0016) \\
0.3036 \\
(0.0015) \\
\mathbf{0 . 3 6 3 6} \\
(\mathbf{0 . 0 0 1 7}) \\
0.3462 \\
(0.0617) \\
0.3008 \\
(0.0017) \\
0.2734 \\
(0.0017)\end{array}$ & $\begin{array}{c}0.5526 \\
(0.0011) \\
0.5361 \\
(0.0010) \\
\mathbf{0 . 5 8 2 9} \\
(\mathbf{0 . 0 0 0 1 1 )} \\
0.5599 \\
(0.0011) \\
0.5177 \\
(0.0012) \\
0.5313 \\
(0.0011)\end{array}$ & $\begin{array}{c}0.4943 \\
(0.0015) \\
\mathbf{0 . 5 6 7 3} \\
(\mathbf{0 . 0 0 2 1 )} \\
0.5215 \\
(0.0022) \\
0.4736 \\
(0.0020) \\
0.4399 \\
(0.0022)\end{array}$ \\
\hline U.K. & $\begin{array}{c}0.6685 \\
(0.0032) \\
\mathbf{0 . 7 2 1 9} \\
(\mathbf{0 . 0 0 3 4 )}) \\
\mathbf{0 . 7 4 2 6} \\
(\mathbf{0 . 0 0 2 5 )} \\
0.7153 \\
(0.0029) \\
0.6028 \\
(0.0035)\end{array}$ & $\begin{array}{c}0.5719 \\
(0.0033) \\
\mathbf{0 . 6 2 8 9} \\
\mathbf{( 0 . 0 0 2 9 )} \\
\mathbf{0 . 6 6 5 9} \\
(\mathbf{0 . 0 0 2 3 )} \\
0.6403 \\
(0.0028) \\
0.5349 \\
(0.0033)\end{array}$ & $\begin{array}{c}0.2608 \\
(0.0014) \\
\mathbf{0 . 2 9 4 1} \\
(\mathbf{0 . 0 0 1 1 )} \\
0.2782 \\
(0.0013)\end{array}$ & & $\begin{array}{c}0.5859 \\
(0.0035) \\
\mathbf{0 . 6 3 6 9} \\
(\mathbf{0 . 0 0 2 4}) \\
0.5339 \\
(0.0027) \\
0.4877 \\
(0.0038)\end{array}$ & $\begin{array}{c}0.3077 \\
(0.0024) \\
0.3249 \\
(0.0026) \\
\mathbf{0 . 3 8 5 0} \\
(\mathbf{0 . 0 0 2 4 )} \\
\mathbf{0 . 4 1 1 5} \\
\mathbf{( 0 . 0 0 2 6 )} \\
0.3587 \\
(0.0019)\end{array}$ & $\begin{array}{c}0.5836 \\
(0.0019) \\
\mathbf{0 . 6 3 6 8} \\
(\mathbf{0 . 0 0 2 2 )} \\
\mathbf{0 . 6 5 7 8} \\
(\mathbf{0 . 0 0 1 8 )} \\
0.6486 \\
(0.0017) \\
0.6120 \\
(0.0019)\end{array}$ & - & $\begin{array}{c}0.1796 \\
(0.0018) \\
0.1910 \\
(0.0019) \\
0.2180 \\
(0.0015) \\
0.2035 \\
(0.0015) \\
0.2316 \\
(0.0019)\end{array}$ & $\begin{array}{c}0.1607 \\
(0.0023) \\
\mathbf{0 . 1 9 4 3} \\
(\mathbf{0 . 0 0 2 2}) \\
0.1518 \\
(0.0019) \\
\mathbf{0 . 1 9 5 0} \\
\mathbf{( 0 . 0 0 2 2 )}\end{array}$ & $\begin{array}{c}0.5703 \\
(0.0025) \\
\mathbf{0 . 6 2 3 5} \\
(\mathbf{0 . 0 0 3 0 )} \\
0.5941 \\
(0.0034) \\
0.6138 \\
(0.0027) \\
0.5110 \\
(0.0034)\end{array}$ & $\begin{array}{c}0.2724 \\
(0.0025) \\
\mathbf{0 . 3 4 1 4} \\
\mathbf{( 0 . 0 0 2 4 )} \\
\mathbf{0 . 4 9 2 8} \\
(\mathbf{0 . 0 0 3 2 )} \\
0.3232 \\
(0.0022)\end{array}$ & $\begin{array}{c}0.7030 \\
(0.0014) \\
0.7258 \\
(0.0015) \\
0.7461 \\
(0.0014) \\
0.7200 \\
(0.0015) \\
0.6978 \\
(0.0012)\end{array}$ & $\begin{array}{c}0.5962 \\
(0.0029) \\
\mathbf{0 . 6 2 6 1} \\
(\mathbf{0 . 0 0 3 0 )} \\
0.6478 \\
(0.0026) \\
0.6123 \\
(0.0023) \\
0.5364 \\
(0.0032)\end{array}$ & $\begin{array}{c}0.3521 \\
(0.0012) \\
0.3687 \\
(0.0014) \\
\mathbf{0 . 3 9 1 7} \\
\mathbf{( 0 . 0 0 1 5 )} \\
0.3793 \\
(0.0011)\end{array}$ & $\begin{array}{c}0.3648 \\
(0.0014) \\
0.3553 \\
(0.0008) \\
\mathbf{0 . 3 8 2 8} \\
(\mathbf{0 . 0 0 1 4 )} \\
0.3683 \\
(0.0011)\end{array}$ \\
\hline Italy & $\begin{array}{c}0.8126 \\
(0.0026) \\
0.7625 \\
(0.0024) \\
\mathbf{0 . 8 1 1 7} \\
(\mathbf{0 . 0 0 2 6 )} \\
0.7762 \\
(0.0020) \\
0.6982 \\
(0.0028)\end{array}$ & $\begin{array}{c}0.7460 \\
(0.0028) \\
0.7212 \\
(0.0026) \\
\mathbf{0 . 7 7 2 9} \\
(\mathbf{0 . 0 0 2 1 )} \\
0.7561 \\
(0.0026) \\
0.6644 \\
(0.0030)\end{array}$ & $\begin{array}{c}0.3558 \\
(0.0011) \\
\mathbf{0 . 4 0 3 1} \\
(\mathbf{0 . 0 0 1 2 )} \\
0.3766 \\
(0.0011) \\
0.305 \\
(0.0015)\end{array}$ & $\begin{array}{c}0.7650 \\
(0.0012) \\
0.7325 \\
(0.0011) \\
\mathbf{0 . 7 8 2 0} \\
(\mathbf{0 . 0 0 1 2 )} \\
0.7495 \\
(0.0009) \\
0.7169 \\
(0.0013)\end{array}$ & & $\begin{array}{c}0.3504 \\
(0.0013) \\
\mathbf{0 . 4 1 8 1} \\
(\mathbf{0 . 0 0 1 6 )} \\
\mathbf{0 . 4 3 8 9} \\
(\mathbf{0 . 0 0 1 5 )} \\
0.4116 \\
(0.0014) \\
0.3929 \\
(0.0017)\end{array}$ & $\begin{array}{c}0.7221 \\
(0.0008) \\
0.7217 \\
(0.0006) \\
0.7555 \\
(0.0007) \\
0.7442 \\
(0.0007) \\
0.7339 \\
(0.0007) \\
0.7255 \\
(0.0007)\end{array}$ & $\begin{array}{c}0.0133 \\
(0.0002) \\
0.0111 \\
(0.0002) \\
0.0139 \\
(0.0002) \\
0.0118 \\
(0,0001)\end{array}$ & $\begin{array}{c}0.2876 \\
(0.0005) \\
\mathbf{0 . 3 2 5 1} \\
(\mathbf{0 . 0 0 0 7 )} \\
0.2972 \\
(0.0007) \\
0.2892 \\
(0.0007)\end{array}$ & $\begin{array}{c}0.2425 \\
(0.0004) \\
0.2466 \\
(0.0005) \\
0.2369 \\
(0.0005) \\
0.2468 \\
(0.0004) \\
0.2425 \\
(0.0005)\end{array}$ & $\begin{array}{c}0.7290 \\
(0.0019) \\
0.6846 \\
(0.0015) \\
\mathbf{0 . 7 2 8 1} \\
(\mathbf{0 . 0 0 1 7 )} \\
0.6944 \\
(0.0013) \\
0.6426 \\
(0.0019)\end{array}$ & $\begin{array}{c}0.3458 \\
(0.0021) \\
\mathbf{0 . 4 0 0 2} \\
(\mathbf{0 . 0 0 2 7}) \\
\mathbf{0 . 4 4 7 6} \\
(0.0023) \\
0.4031 \\
(0.0028) \\
0.3472 \\
(0.0026)\end{array}$ & \begin{tabular}{|c}
0.8728 \\
$(0.0007)$ \\
0.8477 \\
$(0.0006)$ \\
0.8733 \\
$(0.0007)$ \\
0.8679 \\
$(0.0007)$ \\
0.8602 \\
$(0.0007)$ \\
0.8476 \\
$(0.0007)$
\end{tabular} & & $\begin{array}{c}0.5154 \\
(0.0005) \\
0.5277 \\
(0.0005) \\
0.5096 \\
(0.0006) \\
0.5152 \\
(0.0006) \\
0.5216 \\
(0.0005) \\
0.5262 \\
(0.0006)\end{array}$ & $\begin{array}{c}0.4641 \\
(0.0011) \\
0.4356 \\
(0.0009) \\
\mathbf{0 . 4 7 0 6} \\
(\mathbf{0 . 0 0 1 0 )} \\
0.4551 \\
(0.0010) \\
0.4465 \\
(0.0010) \\
0.4194 \\
(0.0011)\end{array}$ \\
\hline $\begin{array}{l}\text { South } \\
\text { Africa }\end{array}$ & $\begin{array}{c}.3919 \\
(0.0022) \\
\mathbf{0 . 4 5 7 6} \\
(\mathbf{0 . 0 0 3 1 )} \\
\mathbf{0 . 4 8 6 9} \\
(\mathbf{0 . 0 0 3 0 )} \\
0.4413 \\
(0.0026) \\
0.3669 \\
(0.0032)\end{array}$ & $\begin{array}{c}0.3582 \\
(0.0017) \\
\mathbf{0 . 4 1 6 9} \\
(\mathbf{0 . 0 0 2 4 )} \\
\mathbf{0 . 4 4 9 1} \\
\mathbf{( 0 . 0 0 1 9 )} \\
0.4080 \\
(0.0022) \\
0.3411 \\
(0.0024)\end{array}$ & $\begin{array}{c}0.2839 \\
(.00003) \\
0.2910 \\
(0.0003) \\
0.2893 \\
(0.0003) \\
0.2848 \\
(0.0003) \\
0.2875 \\
(0.0004)\end{array}$ & $\begin{array}{c}0.4560 \\
(0.0016) \\
0.4449 \\
(0.0016) \\
\mathbf{0 . 5 1 0 4} \\
\mathbf{( 0 . 0 0 1 2 )} \\
0.4778 \\
(0.0016) \\
0.4642 \\
(0.0018)\end{array}$ & $\begin{array}{c}0.2683 \\
(0.0028) \\
\mathbf{0 . 3 6 4 4} \\
\mathbf{( 0 . 0 0 2 5 )} \\
\mathbf{0 . 4 3 8 2} \\
\mathbf{( 0 . 0 0 2 5 )} \\
0.3986 \\
(0.0030) \\
0.3635 \\
(0.0032)\end{array}$ & & $\begin{array}{c}0.4225 \\
(0.0012) \\
\mathbf{0 . 4 8 5 6} \\
\mathbf{( 0 . 0 0 1 5 )} \\
\mathbf{0 . 5 1 2 0} \\
(\mathbf{0 . 0 0 1 3 )} \\
0.4678 \\
(0.0011)\end{array}$ & $\begin{array}{c}0.0135 \\
(0.0001) \\
0.0152 \\
(0.0001) \\
0.0135 \\
(0.0001) \\
0.0144 \\
(0.0001) \\
0.0138 \\
(0.0001)\end{array}$ & $\begin{array}{c}0.2962 \\
(0.0011) \\
0.3149 \\
(0.0013) \\
0.3225 \\
(0.0013) \\
0.3034 \\
(0.0009)\end{array}$ & $\begin{array}{c}0.2583 \\
(0.0005) \\
0.2623 \\
(0.0006) \\
0.2518 \\
(0.0005) \\
0.2643 \\
(0.0006) \\
0.2608 \\
(0.0004)\end{array}$ & $\begin{array}{c}0.3806 \\
(0.0021) \\
\mathbf{0 . 4 3 4 4} \\
(\mathbf{0 . 0 0 3 0 )} \\
\mathbf{0 . 4 4 9 5} \\
(\mathbf{0 . 0 0 2 6 )} \\
0.4012 \\
(0.0027) \\
0.3294 \\
(0.0030)\end{array}$ & $\begin{array}{c}0.3446 \\
(0.0021) \\
\mathbf{0 . 4 2 9 9} \\
\mathbf{( 0 . 0 0 2 8 )} \\
\mathbf{0 . 4 6 4 3} \\
\mathbf{( 0 . 0 0 2 2 )} \\
0.4113 \\
(0.0027) \\
0.3448 \\
(0.0028) \\
\end{array}$ & \begin{tabular}{|c}
0.3507 \\
$(0.0030)$ \\
$\mathbf{0 . 4 3 2 4}$ \\
$\mathbf{( 0 . 0 0 2 6 )}$ \\
$\mathbf{0 . 4 9 1 8}$ \\
$(\mathbf{0 . 0 0 2 0 )}$ \\
0.4612 \\
$(0.0028)$ \\
0.4455 \\
$(0.0030)$
\end{tabular} & $\begin{array}{c}0.3824 \\
(0.0020) \\
0.3590 \\
(0.0019) \\
\mathbf{0 . 4 2 6 4} \\
(\mathbf{0 . 0 0 1 5}) \\
0.3975 \\
(0.0020) \\
0.3467 \\
(0.0022)\end{array}$ & $\begin{array}{c}0.2932 \\
(0.00008) \\
0.3060 \\
(0.0013) \\
0.2945 \\
(0.0009)\end{array}$ & $\begin{array}{c}0.3095 \\
(0.0002) \\
0.3109 \\
(0.0002) \\
0.3148 \\
(0.0002) \\
0.3102 \\
(0.0001)\end{array}$ \\
\hline Germany & $\begin{array}{c}0.7746 \\
(0.0014) \\
0.7510 \\
(0.0013) \\
\mathbf{0 . 7 8 2 3} \\
(\mathbf{0 . 0 0 1 0 )} \\
0.7644 \\
(0.0013) \\
0.7209 \\
(0.0015)\end{array}$ & $\begin{array}{c}0.7261 \\
(0.0017) \\
0.7127 \\
(0.0018) \\
\mathbf{0 . 7 6 8 1} \\
(\mathbf{0 . 0 0 1 4 )} \\
0.7464 \\
(0.0018) \\
0.6938 \\
(0.0020)\end{array}$ & $\begin{array}{c}0.3576 \\
(0.0019) \\
0.3465 \\
(0.0019) \\
\mathbf{0 . 4 0 0 0} \\
(\mathbf{0 . 0 0 1 7}) \\
0.3845 \\
(0.0018) \\
0.3482 \\
(0.0013)\end{array}$ & $\begin{array}{c}0.7609 \\
(0.0012) \\
0.7407 \\
(0.0011) \\
\mathbf{0 . 7 8 3 1} \\
(\mathbf{0 . 0 0 0 9 )} \\
0.7592 \\
(0.0011) \\
0.7375 \\
(0.0012)\end{array}$ & $\begin{array}{c}0.7242 \\
(0.0007) \\
0.7133 \\
(0.0005) \\
0.7398 \\
(0.0005) \\
0.7301 \\
(0.0007) \\
0.7211 \\
(0.0007)\end{array}$ & $\begin{array}{c}0.4253 \\
(0.0013) \\
\mathbf{0 . 4 9 6 3} \\
(\mathbf{0 . 0 0 1 7 )} \\
\mathbf{0 . 5 0 5 6} \\
(\mathbf{0 . 0 0 1 4 )} \\
0.4799 \\
(0.0012)\end{array}$ & & $\begin{array}{c}-0.0135 \\
(0.0004) \\
-0.0258 \\
(0.0005) \\
-0.0160 \\
(0.0004) \\
-0.0221 \\
(0.0005) \\
-0.0185 \\
(0.0005)\end{array}$ & $\begin{array}{c}0.3365 \\
(0.0005) \\
0.3507 \\
(0.0006) \\
0.3599 \\
(0.0005) \\
0.3400 \\
(0.0004)\end{array}$ & $\begin{array}{c}0.2848 \\
(0.0009) \\
0.2673 \\
(0.0012) \\
0.2877 \\
(0.0011) \\
0.2966 \\
(0.0013) \\
0.2862 \\
(0.0012)\end{array}$ & $\begin{array}{c}0.7289 \\
(0.0020) \\
0.6931 \\
(0.0018) \\
\mathbf{0 . 7 5 2 6} \\
(\mathbf{0 . 0 0 2 0 )} \\
0.7411 \\
(0.0020) \\
0.7104 \\
(0.0018) \\
0.6638 \\
(0.0020)\end{array}$ & $\begin{array}{c}0.3752 \\
(0.0026) \\
\mathbf{0 . 4 4 7 0} \\
(\mathbf{0 . 0 0 3 4 )} \\
\mathbf{0 . 5 0 7 2} \\
\mathbf{( 0 . 0 0 2 8 )} \\
0.4106 \\
(0.0033) \\
0.3772 \\
(0.0035)\end{array}$ & \begin{tabular}{|c}
0.8285 \\
$(0.0004)$ \\
0.8186 \\
$(0.0004)$ \\
0.8344 \\
$(0.0003)$ \\
0.8277 \\
$(0.0004)$ \\
0.8222 \\
$(0.0004)$
\end{tabular} & $\begin{array}{c}0.6829 \\
(0.0014) \\
0.6586 \\
(0.0015) \\
\mathbf{0 . 6 9 3 3} \\
(\mathbf{0 . 0 0 1 1 )} \\
0.6761 \\
(0.0013) \\
0.6427 \\
(0.0016)\end{array}$ & $\begin{array}{c}0.5049 \\
(0.0011) \\
0.4832 \\
(0.0010) \\
\mathbf{0 . 5 2 1 7} \\
(\mathbf{0 . 0 0 0 8 )} \\
0.4963 \\
(0.0008)\end{array}$ & $\begin{array}{c}0.4549 \\
(0.0008) \\
0.4472 \\
(0.0005) \\
0.4668 \\
(0.0006) \\
0.4502 \\
(0.0007) \\
0.4452 \\
(0.0008)\end{array}$ \\
\hline China & $\begin{array}{c}-0.0009 \\
(0.0001) \\
-0.0020 \\
(0.0001) \\
-0.0010 \\
(0.0001)\end{array}$ & $\begin{array}{c}-0.0202 \\
(0.0004) \\
-0.0249 \\
(0.0004) \\
-0.0216 \\
(0.0203)\end{array}$ & $\begin{array}{c}0.0032 \\
(0.0006) \\
-0.0079 \\
(0.0008) \\
0.0076 \\
(0.0008) \\
-0.0003 \\
(0.0007) \\
0.0044 \\
(0.0007)\end{array}$ & $\begin{array}{c}-0.0045 \\
(0.0003) \\
-0.0085 \\
(0.0004) \\
-0.0029 \\
(0.0003) \\
-0.0046 \\
(0.0003)\end{array}$ & $\begin{array}{c}0.0137 \\
(0.0004) \\
0.0096 \\
(0.0004) \\
0.0143 \\
(0.0004) \\
0.0100 \\
(0.0003)\end{array}$ & $\begin{array}{l}-0.0060 \\
(0.0003) \\
-0.0106 \\
(0.0003) \\
-0.0071 \\
(0.0002)\end{array}$ & $\begin{array}{l}-0.0235 \\
(0.0002) \\
-0.0202 \\
(0.0002) \\
-0.0234 \\
(0.0002) \\
-0.0209 \\
(0.0003) \\
-0.0221 \\
(0.0002)\end{array}$ & & $\begin{array}{c}-0.0124 \\
(0.0002) \\
-0.0105 \\
(0.0002) \\
-0.0127 \\
(0.0001)\end{array}$ & $\begin{array}{c}0.0701 \\
(0.0010) \\
0.0606 \\
(0.0006) \\
0.0704 \\
(0.0010) \\
0.0626 \\
(0.0007)\end{array}$ & $\begin{array}{c}0.0013 \\
(0.0002) \\
-0.0047 \\
(0.0003) \\
0.0014 \\
(0.0002) \\
-0.0006 \\
(0.0002)\end{array}$ & $\begin{array}{c}0.0024 \\
(0.0007) \\
-0.0059 \\
(0.0009) \\
0.0083 \\
(0.0009) \\
-0.0043 \\
(0.0010) \\
0.0037 \\
(0.0009) \\
\end{array}$ & \begin{tabular}{|c}
-0.0030 \\
$(0.0001)$ \\
-0.0049 \\
$(0.0002)$ \\
-0.0026 \\
$(0.0001)$ \\
-0.0042 \\
$(0.0002)$ \\
-0.0032 \\
$(0.0001)$
\end{tabular} & $\begin{array}{c}0.0094 \\
(0.0002) \\
0.0117 \\
(0.0003) \\
0.0088 \\
(0.0002) \\
0.0000 \\
(0.0002)\end{array}$ & $\begin{array}{c}0.0166 \\
(0.0005) \\
0.0088 \\
(0.0005) \\
0.0204 \\
(0.0005) \\
0.00152 \\
(0.0003)\end{array}$ & $\begin{array}{c}0.0199 \\
(0.0003) \\
0.0166 \\
(0.0003) \\
0.0212 \\
(0.0003) \\
0.0182 \\
(0.0003) \\
0.0196 \\
(0.0002)\end{array}$ \\
\hline
\end{tabular}

contagion effects from Japan were found (see Tables 6 and 7). Therefore, to distinguish the temporal asymmetry of contagion effects in addition to spatial asymmetry, the dynamic behavior of conditional dependence was studied using the Bai and Perron (2003) multiple breakpoints test to determinate structural changes. At the same time, the existence, direction and timing of contagion effects were tested among the present sample markets.

The identified break dates are the moments where a structural change of the conditional dependence between markets emerges. The case of the absence of breakpoints provides proof of the absence of financial pure contagion. Moreover, a structural change should be 
Table 7 (continued)

\begin{tabular}{|c|c|c|c|c|c|c|c|c|c|c|c|c|c|c|c|c|}
\hline India & $\begin{array}{c}0.3001 \\
(0.0011) \\
\mathbf{0 . 3 4 7 2} \\
(\mathbf{0 . 0 0 1 3 )} \\
0.3141 \\
(0.0014) \\
0.2728 \\
(0.0017)\end{array}$ & $\begin{array}{c}0.2111 \\
(0.0038) \\
\mathbf{0 . 2 8 3 8} \\
(\mathbf{0 . 0 0 3 6 )} \\
\mathbf{0 . 3 4 2 5} \\
(\mathbf{0 . 0 0 2 8 )} \\
0.2971 \\
(0.0036) \\
0.1787 \\
(0.0040)\end{array}$ & $\begin{array}{c}0.1636 \\
(0.0012) \\
\mathbf{0 . 1 9 3 4} \\
\mathbf{( 0 . 0 0 1 5 )} \\
\mathbf{0 . 2 1 9 3} \\
\mathbf{( 0 . 0 0 1 3 )} \\
0.1796 \\
(0.0016)\end{array}$ & $\begin{array}{c}0.3453 \\
\\
(0.0002) \\
0.3463 \\
(0.0002) \\
0.3423 \\
(0.0002) \\
0.3455 \\
(0.0002)\end{array}$ & $\begin{array}{c}0.3101 \\
(0.0001) \\
0.3071 \\
(0.0001) \\
0.3089 \\
(0.0001) \\
0.3095 \\
(0.0001)\end{array}$ & $\begin{array}{c}0.3213 \\
(0.0008) \\
0.3366 \\
(0.0010) \\
0.3443 \\
(0.0009) \\
0.3275 \\
(0.0009) \\
0.3343 \\
(0.0010)\end{array}$ & $\begin{array}{c}0.3434 \\
(0.0005) \\
0.3478 \\
(0.0006) \\
0.3675 \\
(0.0004) \\
0.3473 \\
(0.0006) \\
0.3527 \\
(0.0006)\end{array}$ & $\begin{array}{c}-0.0014 \\
(0.0003) \\
-0.0032 \\
(0.0003) \\
-0.0005 \\
(0.0003)\end{array}$ & & $\begin{array}{c}0.2785 \\
(0.0004) \\
0.2891 \\
(0.0005) \\
0.2810 \\
(0.0005) \\
0.2765 \\
(0.0006) \\
0.2795 \\
(0.0005)\end{array}$ & $\begin{array}{c}0.2967 \\
(0.0011) \\
0.2883 \\
(0.0009) \\
0.3195 \\
(0.0008) \\
0.2934 \\
(0.0010) \\
0.2846 \\
(0.0011)\end{array}$ & $\begin{array}{c}0.2851 \\
(0.0010) \\
0.2988 \\
(0.0014) \\
0.3061 \\
(0.0012) \\
0.2882 \\
(0.0010)\end{array}$ & \begin{tabular}{|c}
0.3024 \\
$(0.0009)$ \\
$\mathbf{0 . 3 4 1 9}$ \\
$(\mathbf{0 . 0 0 1 2 )}$ \\
$\mathbf{0 . 3 6 3 5}$ \\
$\mathbf{( 0 . 0 0 1 0 )}$ \\
0.3264 \\
$(0.0008)$
\end{tabular} & $\begin{array}{c}0.2784 \\
(0.0015) \\
\mathbf{0 . 3 0 8 5} \\
(\mathbf{0 . 0 0 2 0}) \\
\mathbf{0 . 3 2 2 6} \\
\mathbf{( 0 . 0 0 1 6 )} \\
0.2902 \\
(0.0018) \\
0.2452 \\
(0.0020)\end{array}$ & $\begin{array}{c}0.1969 \\
(0.0002) \\
0.1894 \\
(0.0003) \\
0.1945 \\
(0.0002)\end{array}$ & $\begin{array}{c}0.2143 \\
(0.0003) \\
0.2048 \\
(0.0002) \\
\mathbf{0 . 2 3 1 7} \\
(\mathbf{0 . 0 0 0 3 )} \\
0.2174 \\
(0.0003)\end{array}$ \\
\hline Japan & $\begin{array}{c}0.2701 \\
(0.0012) \\
0.2832 \\
(0.0014) \\
0.2633 \\
(0.0010) \\
0.2912 \\
(0.0013) \\
0.2821 \\
(0.0012)\end{array}$ & $\begin{array}{c}0.2555 \\
(0.0008) \\
0.2321 \\
(0.0012) \\
0.2455 \\
(0.0011) \\
0.2550 \\
(0.0012) \\
0.2609 \\
(0.0012)\end{array}$ & $\begin{array}{c}0.1212 \\
(0.0004) \\
0.1244 \\
(0.0004)\end{array}$ & $\begin{array}{c}0.2897 \\
(0.0012) \\
0.3000 \\
(0.0011) \\
0.2815 \\
(0.0009) \\
0.3027 \\
(0.0011) \\
0.2944 \\
(0.0011)\end{array}$ & $\begin{array}{c}0.2424 \\
(0.0006) \\
0.2470 \\
(0.0006) \\
0.2332 \\
(0.0006) \\
0.2451 \\
(0.0005) \\
0.2399 \\
(0.0006)\end{array}$ & $\begin{array}{c}0.2651 \\
(0.0005) \\
0.2496 \\
(0.0005) \\
0.2653 \\
(0.0004) \\
0.2616 \\
(0.0006)\end{array}$ & $\begin{array}{c}0.2853 \\
(0.0009) \\
0.2614 \\
(0.0012) \\
0.2770 \\
(0.0011) \\
0.2947 \\
(0.0012) \\
0.2837 \\
(0.0012)\end{array}$ & $\begin{array}{c}0.0783 \\
(0.0005) \\
0.0722 \\
(0.0004) \\
0.0692 \\
(0.0005) \\
0.0771 \\
(0.0004) \\
0.0732 \\
(0.0004)\end{array}$ & $\begin{array}{c}0.2804 \\
(0.0004) \\
0.2928 \\
(0.0004) \\
0.2789 \\
(0.0003)\end{array}$ & & $\begin{array}{c}0.2527 \\
(0.0013) \\
0.2738 \\
(0.0014) \\
0.2537 \\
(0.0013) \\
0.2731 \\
(0.0009) \\
0.2824 \\
(0.0014)\end{array}$ & $\begin{array}{c}0.2116 \\
(0.0005) \\
0.2369 \\
(0.0005) \\
0.2203 \\
(0.0006) \\
0.2083 \\
(0.0005)\end{array}$ & \begin{tabular}{|c}
0.2897 \\
$(0.0010)$ \\
0.2989 \\
$(0.0011)$ \\
0.2821 \\
$(0.0009)$ \\
0.3047 \\
$(0.0010)$ \\
0.2914 \\
$(0.0011)$
\end{tabular} & $\begin{array}{c}0.2776 \\
(0.0009) \\
0.2857 \\
(0.0009) \\
0.2724 \\
(0.0009) \\
0.2817 \\
(0.0007) \\
0.2907 \\
(0.0010)\end{array}$ & $\begin{array}{c}0.1501 \\
(0.0007) \\
0.1582 \\
(0.0007) \\
0.1516 \\
(0.0006) \\
0.1550 \\
(0.0005)\end{array}$ & $\begin{array}{c}0.1548 \\
(0.0003) \\
0.1574 \\
(0.0004)\end{array}$ \\
\hline Sweden & $\begin{array}{c}0.7900 \\
(0.0002) \\
0.7878 \\
(0.0002) \\
0.7918 \\
(0.0002) \\
0.7887 \\
(0.0002) \\
0.7874 \\
(0.0002)\end{array}$ & $\begin{array}{c}0.7011 \\
(0.0014) \\
0.7133 \\
(0.0013) \\
0.7400 \\
(0.0012) \\
0.7504 \\
(0.0012) \\
0.7358 \\
(0.0013) \\
0.7247 \\
(0.0014)\end{array}$ & $\begin{array}{c}0.3361 \\
(0.0032) \\
0.2866 \\
(0.0033) \\
\mathbf{0 . 3 9 2 0} \\
\mathbf{( 0 . 0 0 2 9 )} \\
0.3635 \\
(0.0029) \\
0.3190 \\
(0.0032) \\
0.2352 \\
(0.0033)\end{array}$ & $\begin{array}{c}0.7436 \\
(0.0024) \\
0.7297 \\
(0.0022) \\
\mathbf{0 . 7 7 7 5} \\
(\mathbf{0 . 0 0 2 3 )} \\
0.7485 \\
(0.0019) \\
0.6559 \\
(0.0026)\end{array}$ & $\begin{array}{c}0.7048 \\
(0.0017) \\
0.6836 \\
(0.0014) \\
\mathbf{0 . 7 2 3 6} \\
\mathbf{( 0 . 0 0 1 3 )} \\
0.7073 \\
(0.0016) \\
0.6593 \\
(0.0017)\end{array}$ & $\begin{array}{c}0.3615 \\
(0.0031) \\
\mathbf{0 . 4 5 6 9} \\
(\mathbf{0 . 0 0 2 7 )} \\
0.4187 \\
(0.0036) \\
0.3042 \\
(0.0042)\end{array}$ & $\begin{array}{c}0.6996 \\
(0.0018) \\
0.7159 \\
(0.0018) \\
\mathbf{0 . 7 5 6 3} \\
(\mathbf{0 . 0 0 1 8 )} \\
\mathbf{0 . 7 7 2 9} \\
(\mathbf{0 . 0 0 1 6 )} \\
0.7373 \\
(0.0017) \\
0.6875 \\
(0.0019)\end{array}$ & $\begin{array}{c}0.0122 \\
(0.0006) \\
-0.0060 \\
(0.0007) \\
0.0119 \\
(0.0005) \\
0.0058 \\
(0.0005)\end{array}$ & $\begin{array}{c}0.2977 \\
(0.0007) \\
0.3092 \\
(0.0009) \\
0.3162 \\
(0.0009) \\
0.3045 \\
(0.0008) \\
0.2967 \\
(0.0007)\end{array}$ & $\begin{array}{c}0.2593 \\
(0.0006) \\
0.2537 \\
(0.0008) \\
0.2686 \\
(0.0009) \\
0.2596 \\
(0.0008) \\
0.2702 \\
(0.0009)\end{array}$ & & $\begin{array}{c}0.3568 \\
(0.0020) \\
\mathbf{0 . 4 3 6 1} \\
(\mathbf{0 . 0 0 2 6}) \\
\mathbf{0 . 4 7 5 4} \\
\mathbf{( 0 . 0 0 2 2 )} \\
0.4141 \\
(0.0019)\end{array}$ & \begin{tabular}{|c}
0.7997 \\
$(0.0014)$ \\
0.7851 \\
$(0.0012)$ \\
$\mathbf{0 . 8 1 1 7}$ \\
$\mathbf{( 0 . 0 0 1 1 )}$ \\
0.7969 \\
$(0.0014)$ \\
0.7495 \\
$(0.0015)$
\end{tabular} & $\begin{array}{c}0.7238 \\
(0.0011) \\
0.7111 \\
(0.0012) \\
0.7331 \\
(0.0009) \\
0.7098 \\
(0.0012) \\
0.7192 \\
(0.0012)\end{array}$ & $\begin{array}{c}0.4940 \\
(0.0010) \\
0.4804 \\
(0.0009) \\
\mathbf{0 . 5 1 9 4} \\
(\mathbf{0 . 0 0 1 0 )} \\
0.4960 \\
(0.0010) \\
0.4742 \\
(0.0012)\end{array}$ & $\begin{array}{c}0.4531 \\
(0.0000) \\
0.4529 \\
(0.0000) \\
0.4536 \\
(0.0000) \\
0.4530 \\
(0.0000) \\
0.4529 \\
(0.0000)\end{array}$ \\
\hline Russia & $\begin{array}{c}0.4674 \\
(0.0011) \\
0.4089 \\
(0.0011) \\
\mathbf{0 . 4 7 7 8} \\
(\mathbf{0 . 0 0 0 7 )} \\
0.4472 \\
(0.0011)\end{array}$ & $\begin{array}{c}0.3942 \\
(0.0017) \\
0.3388 \\
(0.0017) \\
\mathbf{0 . 4 3 1 6} \\
(\mathbf{0 . 0 0 1 7 )} \\
\mathbf{0 . 4 5 7 6} \\
(\mathbf{0 . 0 0 1 4 )} \\
0.3983 \\
(0.0016)\end{array}$ & $\begin{array}{c}0.2419 \\
(0.0018) \\
\mathbf{0 . 3 0 6 0} \\
(\mathbf{0 . 0 0 2 1 )} \\
\mathbf{0 . 3 2 0 3} \\
\mathbf{( 0 . 0 0 2 1 )} \\
0.2940 \\
(0.0022) \\
0.2724 \\
(0.0024)\end{array}$ & $\begin{array}{c}0.4589 \\
(0.0015) \\
0.4159 \\
(0.0015) \\
\mathbf{0 . 4 7 4 7} \\
(\mathbf{0 . 0 0 1 5 )} \\
\mathbf{0 . 4 9 5 4} \\
(\mathbf{0 . 0 0 1 3 )} \\
0.4466 \\
(0.0014) \\
0.4365 \\
(0.0015)\end{array}$ & $\begin{array}{c}0.3762 \\
(0.0017) \\
\mathbf{0 . 4 1 9 0} \\
\mathbf{( 0 . 0 0 2 3 )} \\
\mathbf{0 . 4 6 5 5} \\
\mathbf{( 0 . 0 0 2 1 )} \\
0.4236 \\
(0.0024) \\
0.3731 \\
(0.0022)\end{array}$ & $\begin{array}{c}0.3686 \\
(0.0018) \\
\mathbf{0 . 4 4 9 2} \\
(\mathbf{0 . 0 0 2 3 )} \\
\mathbf{0 . 4 6 7 5} \\
\mathbf{( 0 . 0 0 2 1 )} \\
0.4258 \\
(0.0020) \\
0.3725 \\
(0.0024)\end{array}$ & $\begin{array}{c}0.4094 \\
(0.0018) \\
\mathbf{0 . 4 8 1 9} \\
(\mathbf{0 . 0 0 2 5 )} \\
\mathbf{0 . 5 1 7 5} \\
(\mathbf{0 . 0 0 2 1 )} \\
0.4253 \\
(0.0024) \\
0.4125 \\
(0.0026)\end{array}$ & $\begin{array}{c}-0.0040 \\
(0.0011) \\
0.0082 \\
(0.0011) \\
-0.0045 \\
(0.0011) \\
0.0113 \\
(0.0011) \\
-0.0026 \\
(0.0011) \\
0.0058 \\
(0.0010)\end{array}$ & $\begin{array}{c}0.2786 \\
(0.0014) \\
\mathbf{0 . 3 0 6 9} \\
\mathbf{( 0 . 0 0 1 6 )} \\
0.2955 \\
(0.0019) \\
0.2793 \\
(0.0013)\end{array}$ & $\begin{array}{c}0.2209 \\
(0.0004) \\
0.2165 \\
(0.0004) \\
0.2319 \\
(0.0003) \\
0.2236 \\
(0.0003) \\
0.2146 \\
(0.0003)\end{array}$ & $\begin{array}{c}0.4346 \\
(0.0019) \\
0.3489 \\
(0.0019) \\
\mathbf{0 . 4 6 2 3} \\
\mathbf{( 0 . 0 0 1 8 )} \\
0.4016 \\
(0.0019) \\
0.4233 \\
(0.0018)\end{array}$ & & $\begin{array}{c}0.4526 \\
(0.0020) \\
0.3931 \\
(0.0020) \\
\mathbf{0 . 4 7 5 1} \\
\mathbf{( 0 . 0 0 1 9 )} \\
0.4196 \\
(0.0015)\end{array}$ & $\begin{array}{c}0.3787 \\
(0.0019) \\
0.3232 \\
(0.0019) \\
\mathbf{0 . 3 9 4 8} \\
(\mathbf{0 . 0 0 1 9 )} \\
\mathbf{0 . 4 1 7 8} \\
(\mathbf{0 . 0 0 1 6 )} \\
0.3458 \\
(0.0019) \\
\mathbf{0 . 3 7 2 5} \\
(\mathbf{0 . 0 0 1 8 )}\end{array}$ & $\begin{array}{c}0.2913 \\
(0.0014) \\
0.2373 \\
(0.0013) \\
\mathbf{0 . 3 0 7 9} \\
\mathbf{( 0 . 0 0 1 3 )} \\
\mathbf{0 . 3 3 0 8} \\
\mathbf{( 0 . 0 0 1 5 )} \\
0.2885 \\
(0.0014) \\
0.2732 \\
(0.0015)\end{array}$ & $\begin{array}{c}0.3325 \\
(0.0013) \\
0.2805 \\
(0.0013) \\
\mathbf{0 . 3 4 4 9} \\
(\mathbf{0 . 0 0 1 3 )} \\
\mathbf{0 . 3 6 5 3} \\
\mathbf{( 0 . 0 0 1 1 )} \\
0.3253 \\
(0.0013) \\
\mathbf{0 . 3 4 2 5} \\
(\mathbf{0 . 0 0 1 2})\end{array}$ \\
\hline France & $\begin{array}{c}0.9175 \\
(0.0047) \\
0.8965 \\
(0.0023) \\
0.7634 \\
(0.0050)\end{array}$ & $\begin{array}{c}0.8057 \\
(0.0050) \\
\mathbf{0 . 8 5 3 2} \\
(\mathbf{0 . 0 0 3 8 )} \\
0.5970 \\
(0.0072)\end{array}$ & $\begin{array}{c}0.3827 \\
(0.0012) \\
\mathbf{0 . 4 4 5 5} \\
\mathbf{( 0 . 0 0 1 4 )} \\
0.4288 \\
(0.0016) \\
0.3996 \\
(0.0016) \\
0.3797 \\
(0.0017)\end{array}$ & $\begin{array}{c}0.8667 \\
(0.0011) \\
0.8472 \\
(0.0011) \\
\mathbf{0 . 8 7 9 1} \\
(\mathbf{0 . 0 0 1 1 )} \\
0.8660 \\
(0.0012) \\
0.8426 \\
(0.0009)\end{array}$ & $\begin{array}{c}0.8641 \\
(0.0005) \\
0.8500 \\
(0.0004) \\
0.8657 \\
(0.0005) \\
0.8708 \\
(0.0005) \\
0.8647 \\
(0.0005) \\
0.8569 \\
(0.0005)\end{array}$ & $\begin{array}{c}0.4244 \\
(0.0014) \\
\mathbf{0 . 4 8 6 2} \\
(\mathbf{0 . 0 0 1 8 )} \\
\mathbf{0 . 4 9 6 6} \\
(\mathbf{0 . 0 0 1 7 )} \\
0.4687 \\
(0.0012)\end{array}$ & $\begin{array}{c}0.8235 \\
(0.0006) \\
\mathbf{0 . 8 5 3 9} \\
(\mathbf{0 . 0 0 0 5 )} \\
0.8364 \\
(0.0006)\end{array}$ & $\begin{array}{c}-0.0011 \\
(0.0006) \\
-0.0143 \\
(0.0006) \\
0.0023 \\
(0.0006) \\
-0.0089 \\
(0.0006) \\
-0.0043 \\
(0.0005)\end{array}$ & $\begin{array}{c}0.3325 \\
(0.0001) \\
0.3299 \\
(0.0001) \\
0.3320 \\
(0.0001)\end{array}$ & $\begin{array}{c}0.2900 \\
(0.0006) \\
0.2827 \\
(0.0007) \\
0.2918 \\
(0.0007) \\
0.2994 \\
(0.0008) \\
0.2886 \\
(0.0008)\end{array}$ & $\begin{array}{c}0.8107 \\
(0.0013) \\
0.7818 \\
(0.0011) \\
\mathbf{0 . 8 1 0 4} \\
(\mathbf{0 . 0 0 1 3 )} \\
0.8003 \\
(0.0013) \\
0.7857 \\
(0.0012) \\
0.7546 \\
(0.0013)\end{array}$ & $\begin{array}{c}0.4274 \\
(0.0029) \\
0.3727 \\
(0.0029) \\
\mathbf{0 . 4 5 4 0} \\
(\mathbf{0 . 0 0 2 9 )} \\
\mathbf{0 . 4 9 5 3} \\
\mathbf{( 0 . 0 0 2 4 )} \\
0.4168 \\
(0.0027) \\
0.3968 \\
(0.0029)\end{array}$ & & $\begin{array}{c}0.8041 \\
(0.0045) \\
0.7613 \\
(0.0044) \\
\mathbf{0 . 8 0 2 9} \\
(\mathbf{0 . 0 0 3 6 )} \\
0.7657 \\
(0.0039) \\
0.6458 \\
(0.0048)\end{array}$ & $\begin{array}{c}0.5662 \\
(0.0004) \\
0.5740 \\
(0.0004) \\
0.5607 \\
(0.0004) \\
0.5635 \\
(0.0005) \\
0.5714 \\
(0.0003)\end{array}$ & $\begin{array}{c}0.4970 \\
(0.0008) \\
0.4778 \\
(0.0006) \\
\mathbf{0 . 5 0 4 2} \\
(\mathbf{0 . 0 0 0 8 )} \\
0.4953 \\
(0.0007) \\
0.4760 \\
(0.0006)\end{array}$ \\
\hline Switzerland & $\begin{array}{c}0.8036 \\
(0.0007) \\
0.7881 \\
(0.0006) \\
\mathbf{0 . 8 0 4 3} \\
(\mathbf{0 . 0 0 0 5 )} \\
0.7867 \\
(0.0007) \\
0.7940 \\
(0.0006)\end{array}$ & $\begin{array}{c}0.7356 \\
(0.0010) \\
0.7240 \\
(0.0011) \\
\mathbf{0 . 7 6 0 1} \\
(\mathbf{0 . 0 0 0 8 )} \\
0.7287 \\
(0.0012) \\
0.7400 \\
(0.0011)\end{array}$ & $\begin{array}{c}0.3062 \\
(0.0026) \\
\mathbf{0 . 3 6 6 3} \\
\mathbf{( 0 . 0 0 2 6 )} \\
0.2982 \\
(0.0038) \\
0.1758 \\
(0.0039)\end{array}$ & $\begin{array}{c}0.7608 \\
(0.0052) \\
0.7258 \\
(0.0047) \\
\mathbf{0 . 7 8 5 8} \\
(0.0039) \\
0.7316 \\
(0.0049) \\
0.5534 \\
(0.0055)\end{array}$ & $\begin{array}{c}0.7051 \\
(0.0021) \\
0.6699 \\
(0.0019) \\
\mathbf{0 . 7 1 9 0} \\
\mathbf{( 0 . 0 0 1 6 )} \\
0.6886 \\
(0.0021) \\
0.6275 \\
(0.0023)\end{array}$ & $\begin{array}{c}0.3649 \\
(0.0020) \\
\mathbf{0 . 4 2 9 4} \\
(\mathbf{0 . 0 0 2 5 )} \\
\mathbf{0 . 4 5 6 5} \\
\mathbf{( 0 . 0 0 2 3 )} \\
0.4193 \\
(0.0022) \\
0.3668 \\
(0.0027)\end{array}$ & $\begin{array}{c}0.6799 \\
(0.0012) \\
\mathbf{0 . 7 2 9 1} \\
(\mathbf{0 . 0 0 1 2 )} \\
0.6926 \\
(0.0016) \\
0.6587 \\
(0.0018)\end{array}$ & $\begin{array}{c}0.0132 \\
(0.0005) \\
0.0185 \\
(0.0006) \\
0.0098 \\
(0.0006) \\
0.0134 \\
(0.0003)\end{array}$ & $\begin{array}{c}0.2739 \\
(0.0015) \\
\mathbf{0 . 3 3 2 0} \\
(\mathbf{0 . 0 0 1 6 )} \\
0.3178 \\
(0.0021) \\
0.2915 \\
(0.0019) \\
0.2392 \\
(0.0021)\end{array}$ & $\begin{array}{c}0.2835 \\
(0.0002) \\
0.2846 \\
(0.0002) \\
0.2812 \\
(0.0003) \\
0.2839 \\
(0.0002) \\
0.2862 \\
(0.0003)\end{array}$ & $\begin{array}{c}0.7359 \\
(0.0008) \\
0.7189 \\
(0.0007) \\
\mathbf{0 . 7 3 9 5} \\
(\mathbf{0 . 0 0 0 6 )} \\
0.7158 \\
(0.0008) \\
0.7250 \\
(0.0007)\end{array}$ & $\begin{array}{c}0.3600 \\
(0.0023) \\
0.3144 \\
(0.0023) \\
\mathbf{0 . 4 0 2 7} \\
(\mathbf{0 . 0 0 2 3 )} \\
\mathbf{0 . 4 3 5 9} \\
(\mathbf{0 . 0 0 1 9 )} \\
0.3620 \\
(0.0023) \\
0.3751 \\
(0.0022)\end{array}$ & \begin{tabular}{|c|c}
0.8039 \\
$(0.0020)$ \\
0.7693 \\
$(0.0018)$ \\
$\mathbf{0 . 8 1 1 1}$ \\
$(\mathbf{0 . 0 0 0 1 5})$ \\
0.7784 \\
$(0.0019)$ \\
0.7337 \\
$(0.0021)$ \\
\end{tabular} & & $\begin{array}{c}0.4734 \\
(0.0012) \\
0.4551 \\
(0.0010) \\
\mathbf{0 . 4 9 3 1} \\
\mathbf{( 0 . 0 0 0 9 )} \\
0.4658 \\
(0.0011) \\
0.4536 \\
(0.0012)\end{array}$ & $\begin{array}{c}0.4225 \\
(0.0005) \\
0.4165 \\
(0.0004) \\
0.4279 \\
(0.0004) \\
0.4167 \\
(0.0005) \\
0.4187 \\
(0.0005)\end{array}$ \\
\hline U.S. & $\begin{array}{c}0.5419 \\
(0.0002) \\
0.5455 \\
(0.0001) \\
0.5414 \\
(0.0001) \\
0.5440 \\
(0.0001) \\
0.5455 \\
(0.0002)\end{array}$ & $\begin{array}{c}0.5004 \\
(0.0019) \\
0.4692 \\
(0.0016) \\
\mathbf{0 . 5 2 8 5} \\
(\mathbf{0 . 0 0 1 4 )} \\
0.5024 \\
(0.0018) \\
0.4417 \\
(0.0019)\end{array}$ & $\begin{array}{c}0.5473 \\
(0.0011) \\
0.5356 \\
(0.0013) \\
\mathbf{0 . 5 7 2 9} \\
\mathbf{( 0 . 0 0 1 3 )} \\
0.5502 \\
(0.0013) \\
0.5209 \\
(0.0013) \\
0.5278 \\
(0.0012) \\
\end{array}$ & $\begin{array}{c}0.5522 \\
(0.0009) \\
0.5684 \\
(0.0007) \\
0.5411 \\
(0.0006) \\
0.5581 \\
(0.0008) \\
0.0630 \\
(0.0009)\end{array}$ & $\begin{array}{c}0.5344 \\
(0.0004) \\
0.5413 \\
(0.0003) \\
0.5284 \\
(0.0003) \\
0.5365 \\
(0.0004) \\
0.5392 \\
(0.0004)\end{array}$ & $\begin{array}{c}0.3028 \\
(0.0007) \\
0.2976 \\
(0.0007) \\
0.3055 \\
(0.0007) \\
0.3104 \\
(0.0006) \\
0.3007 \\
(0.0007) \\
0.3055 \\
(0.0006) \\
\end{array}$ & $\begin{array}{c}0.5188 \\
(0.0002) \\
0.5166 \\
(0.0002) \\
0.5208 \\
(0.0002) \\
0.5241 \\
(0.0002) \\
0.5186 \\
(0.0002) \\
0.5196 \\
(0.0002)\end{array}$ & $\begin{array}{c}0.0118 \\
(0.0001) \\
0.0126 \\
(0.0001) \\
0.0115 \\
(0.0001) \\
0.0119 \\
(0.0000)\end{array}$ & $\begin{array}{c}0.2021 \\
(0.0011) \\
0.2117 \\
(0.0013) \\
0.1841 \\
(0.0012) \\
0.1909 \\
(0.0013) \\
0.1995 \\
(0.0009)\end{array}$ & $\begin{array}{c}0.1544 \\
(0.0008) \\
0.1703 \\
(0.0008) \\
0.1610 \\
(0.0005) \\
0.1654 \\
(0.0009)\end{array}$ & $\begin{array}{c}0.5075 \\
(0.0005) \\
0.4942 \\
(0.0005) \\
0.5033 \\
(0.0004) \\
0.5092 \\
(0.0004) \\
0.5005 \\
(0.0004) \\
0.4948 \\
(0.0005) \\
\end{array}$ & $\begin{array}{c}0.2861 \\
(0.0018) \\
0.2532 \\
(0.0015) \\
\mathbf{0 . 3 4 2 2} \\
(\mathbf{0 . 0 0 1 5 )} \\
0.3033 \\
(0.0018) \\
0.2810 \\
(0.0019)\end{array}$ & \begin{tabular}{|c}
0.5766 \\
$(0.0004)$ \\
0.5874 \\
$(0.0003)$ \\
0.5736 \\
$(0.0003)$ \\
0.5814 \\
$(0.0004)$ \\
0.5847 \\
$(0.0004)$
\end{tabular} & $\begin{array}{c}0.4727 \\
(0.0004) \\
0.4642 \\
(0.0004) \\
0.4743 \\
(0.0003) \\
0.4677 \\
(0.0004) \\
0.4647 \\
(0.0004)\end{array}$ & & $\begin{array}{c}0.6744 \\
(0.0010) \\
0.6551 \\
(0.0009) \\
\mathbf{0 . 6 8 0 3} \\
(\mathbf{0 . 0 0 1 0 )} \\
0.6696 \\
(0.00010) \\
0.6564 \\
(0.0010) \\
0.6250 \\
(0.0010) \\
\end{array}$ \\
\hline Canada & $\begin{array}{c}0.4876 \\
(0.0013) \\
\mathbf{0 . 5 4 1 2} \\
(\mathbf{0 . 0 0 1 1 )} \\
0.5210 \\
(0.0009) \\
0.5380 \\
(0.0013) \\
0.5306 \\
(0.0012)\end{array}$ & $\begin{array}{c}0.4672 \\
(0.0003) \\
0.4727 \\
(0.0003) \\
0.4682 \\
(0.0003) \\
0.4650 \\
(0.0003) \\
0.4701 \\
(0.0002)\end{array}$ & $\begin{array}{c}0.4950 \\
(0.0015) \\
\mathbf{0 . 5 4 2 4} \\
(\mathbf{0 . 0 0 1 9 )} \\
0.5135 \\
(0.0021) \\
0.4755 \\
(0.0020) \\
0.4422 \\
(0.0022)\end{array}$ & $\begin{array}{c}0.5051 \\
(0.0006) \\
0.5241 \\
(0.0006) \\
0.5118 \\
(0.0005) \\
0.5052 \\
(0.0006) \\
0.5167 \\
(0.0006) \\
0.5200 \\
(0.0006) \\
\end{array}$ & $\begin{array}{c}0.4515 \\
(0.0007) \\
0.4614 \\
(0.0006) \\
0.4779 \\
(0.0005) \\
0.4669 \\
(0.0006) \\
0.4502 \\
(0.0007)\end{array}$ & $\begin{array}{c}0.3176 \\
(0.0000) \\
0.3171 \\
(0.0000) \\
0.3167 \\
(0.0000) \\
0.3175 \\
(0.0001) \\
0.3172 \\
(0.0000)\end{array}$ & $\begin{array}{c}0.4740 \\
(0.0002) \\
0.4721 \\
(0.0001) \\
0.4748 \\
(0.0001) \\
0.4769 \\
(0.0001) \\
0.4732 \\
(0.0001)\end{array}$ & $\begin{array}{c}0.0151 \\
(0.0000) \\
0.0158 \\
(0.0001) \\
0.0150 \\
(0.0001) \\
0.0153 \\
(0.0001) \\
0.0149 \\
(0.0001) \\
0.0154 \\
(0.0001)\end{array}$ & $\begin{array}{c}0.2061 \\
(0.0003) \\
0.2048 \\
(0.0003) \\
0.2025 \\
(0.0003) \\
0.2056 \\
(0.0003) \\
0.2076 \\
(0.0004)\end{array}$ & $\begin{array}{c}0.1541 \\
(0.0008) \\
0.1746 \\
(0.0009) \\
0.1772 \\
(0.0009) \\
0.1658 \\
(0.0009) \\
\mathbf{0 . 1 8 1 7} \\
(\mathbf{0 . 0 0 0 9 9}) \\
0.1656 \\
(0.0009)\end{array}$ & $\begin{array}{c}0.4651 \\
(0.0008) \\
\mathbf{0 . 4 8 4 1} \\
(\mathbf{0 . 0 0 0 8 )} \\
0.4756 \\
(0.0006) \\
0.4685 \\
(0.0008) \\
0.4797 \\
(0.0005)\end{array}$ & $\begin{array}{c}0.3342 \\
(0.0012) \\
0.2703 \\
(0.0012) \\
\mathbf{0 . 3 4 8 8} \\
\mathbf{( 0 . 0 0 1 2 )} \\
\mathbf{0 . 3 6 5 0} \\
(\mathbf{0 . 0 0 1 0 )} \\
0.3393 \\
(0.0012) \\
0.3495 \\
(0.0011) \\
\end{array}$ & \begin{tabular}{|c}
0.5044 \\
$(0.0002)$ \\
0.5108 \\
$(0.0002)$ \\
0.5074 \\
$(0.0002)$ \\
0.5046 \\
$(0.0002)$ \\
0.5086 \\
$(0.0002)$ \\
0.5105 \\
$(0.0002)$ \\
\end{tabular} & $\begin{array}{c}0.4309 \\
(0.0001) \\
0.4278 \\
(0.0001) \\
0.4294 \\
(0.0001) \\
0.4302 \\
(0.0001) \\
0.4281 \\
(0.0001) \\
0.4291 \\
(0.0001) \\
\end{array}$ & $\begin{array}{c}0.6893 \\
(0.0011) \\
0.6625 \\
(0.0010) \\
\mathbf{0 . 6 8 2 9} \\
(\mathbf{0 . 0 0 0 8 )} \\
0.6673 \\
(0.0011) \\
0.6339 \\
(0.0011)\end{array}$ & \\
\hline
\end{tabular}

This table shows the level of dependence for each period. The sample was devised following the breakpoint dates from the previous table. *correspond to a presence of breakpoints without increase in level of dependence. Bold value signifies the timing of unidirectional contagion from market A to market B 


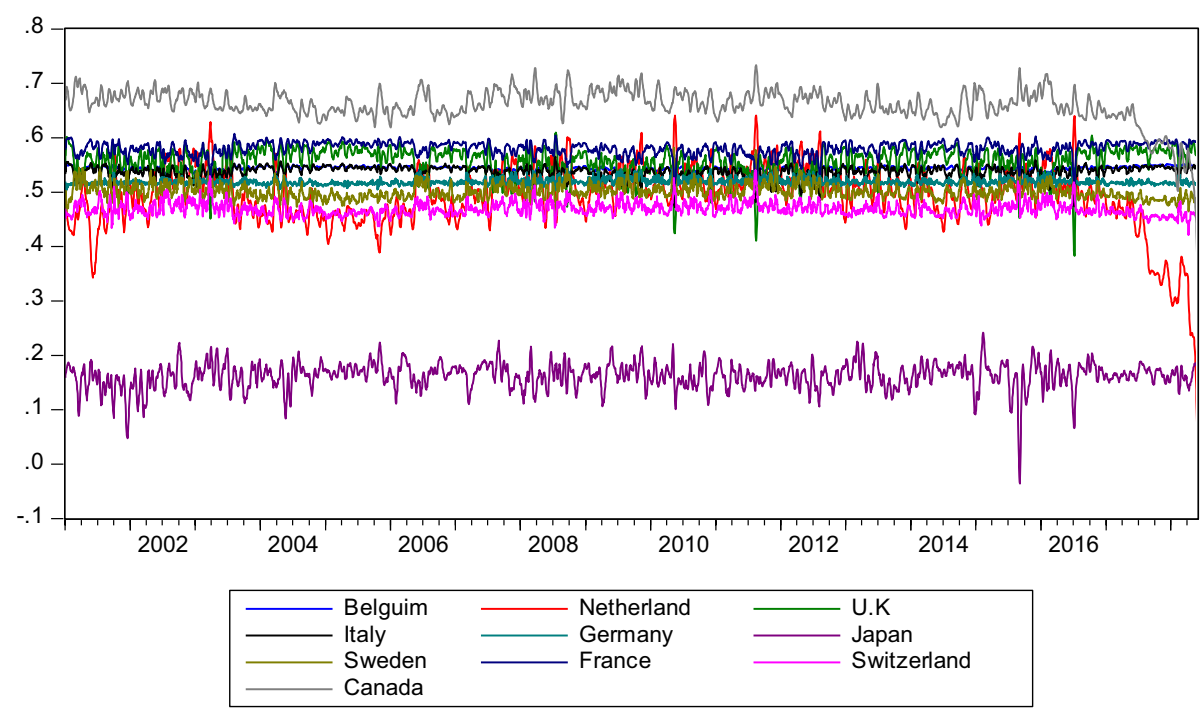

Fig. 1 Conditional dynamic dependencies between the U.S. and other mature markets

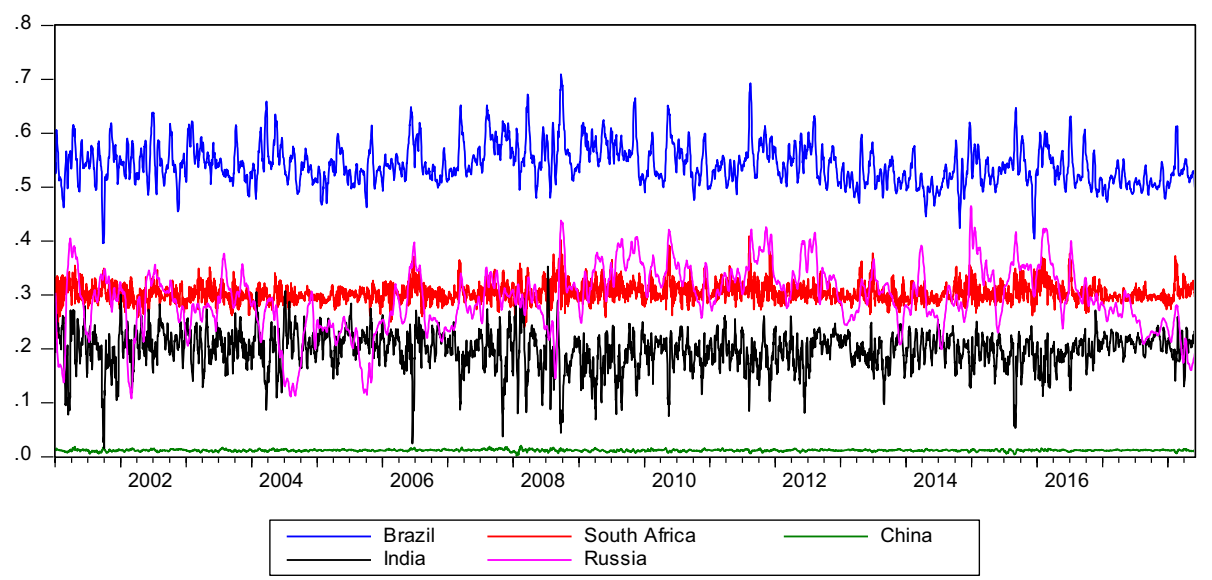

Fig. 2 Dynamic dependencies between the U.S. and BRICS markets

coupled with an increase of unidirectional dependence to confirm the existence of pure contagion effects on this period in comparison with the previous period. In fact, the main contribution of our work is to determinate the timing ${ }^{7}$ of contagion effect in addition to the direction. ${ }^{8}$ We highlight the fact that this is the first paper to propose measuring the structural change of financial dependence using conditional dynamic copulas to detect the presence, direction and time of pure financial contagion.

\footnotetext{
7 Enable the detection of temporal asymmetry of pure contagion effects.

${ }^{8}$ Enable the detection of spatial asymmetry of pure contagion effects.
} 


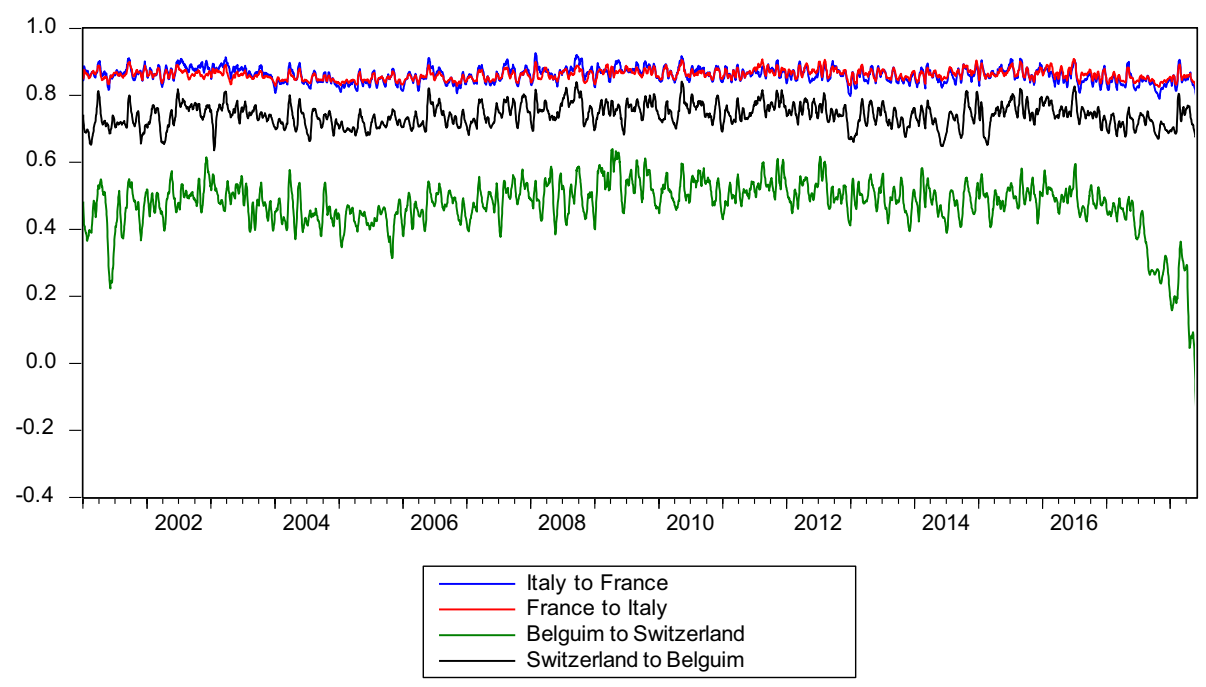

Fig. 3 Conditional dynamic dependencies between certain European markets

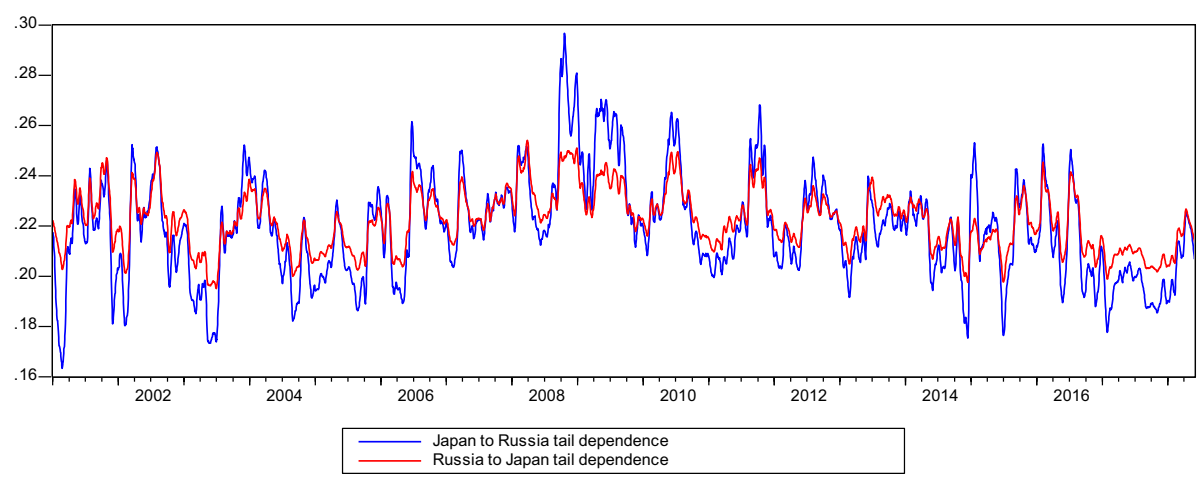

Fig. 4 Conditional dynamic dependencies between Russian and Japanese stock markets

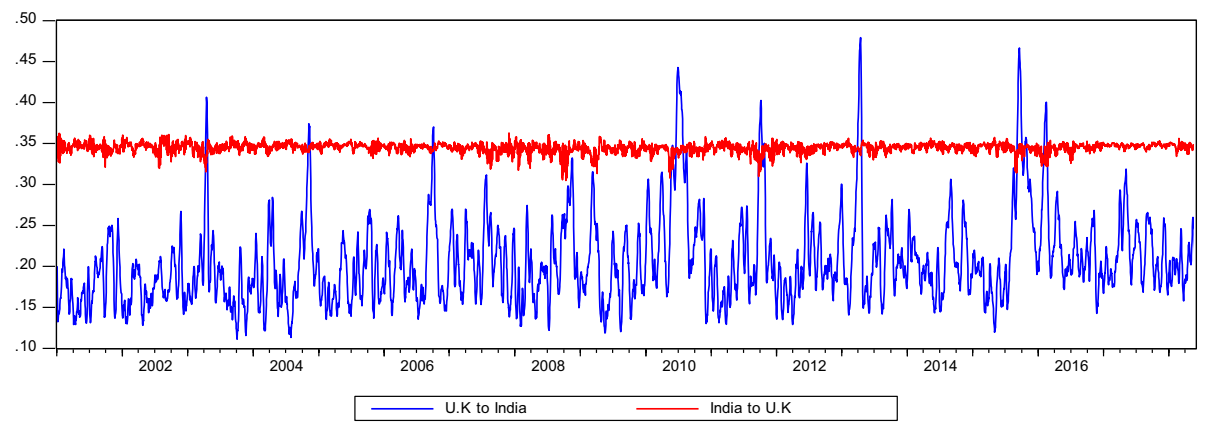

Fig. 5 Dynamic dependencies between U.K. and Indian stock markets via conditional dynamic gaussian copula 


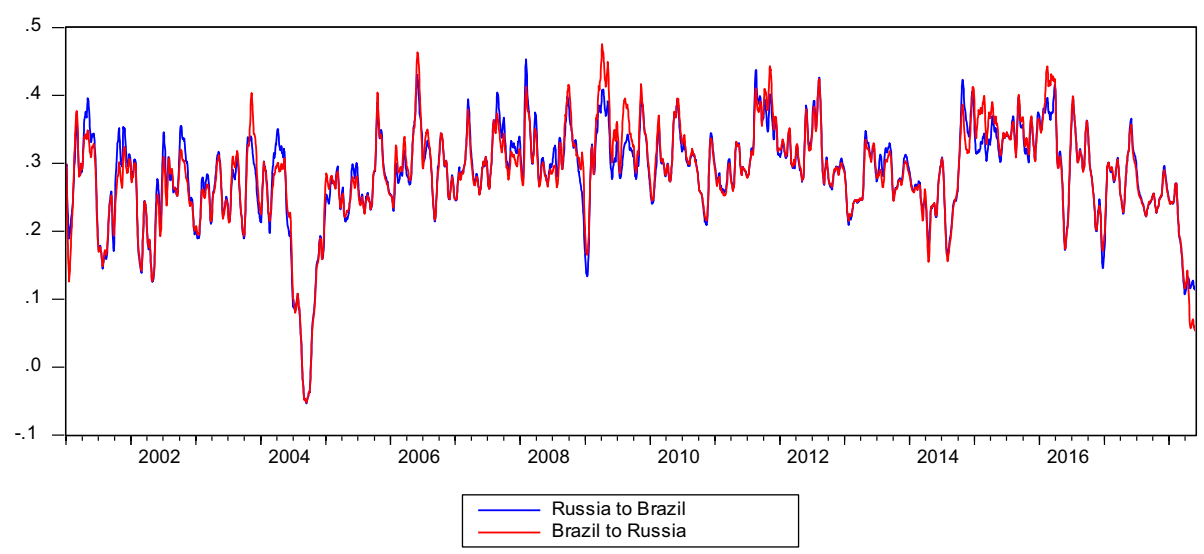

Fig. 6 Dynamic dependencies between Russian and Brazilian stock markets via conditional dynamic gaussian copula

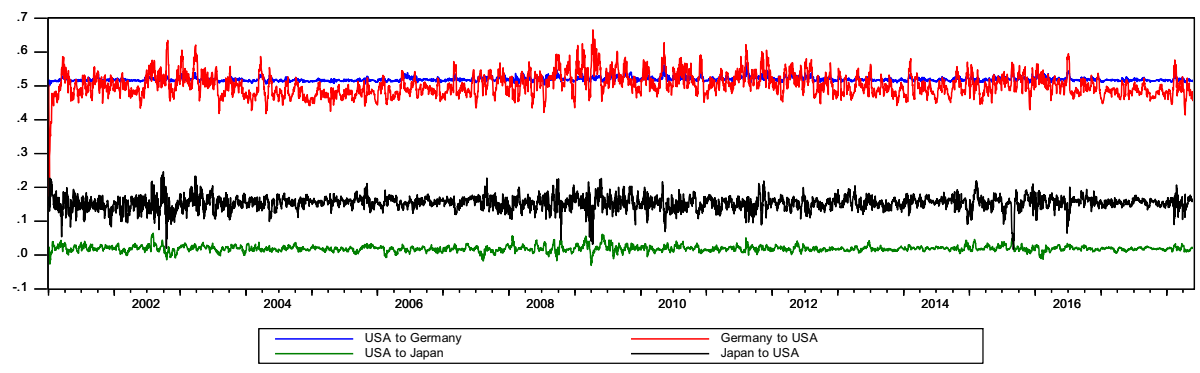

Fig. 7 Dynamic dependencies between German and Japanese and US stock markets via conditional dynamic gaussian copula

According to the results of Tables 6 and 7 and Figs. 1, 2, 3, 4, 5, 6, 7, we conclude the existence of both spatial and temporal ${ }^{9}$ asymmetry for bilateral contagion stock market levels. This shows the importance of taking into account temporal asymmetry to detect the contagion effect of every crisis and to estimate the period of pure contagion related to the investor's behavior. Identification of these asymmetries gives international investors the opportunity to enhance their portfolio strategies. This reveals the role played by conditional information during periods of high volatility, as highlighted by Batten et al. (2019), in outperforming passive portfolio investment strategies, particularly for emerging markets.

In Fig. 2, we highlight the fact that, during stress periods, BRICS financial markets have different relationships with the US market related to their vulnerabilities to international risks. Our results extend the finding of Glasserman and Young (2015) that spillover effects are more exposed when the couple is heterogeneous with a high level of connectivity or linkages between markets.

Moreover, during the global financial crisis, the US market only transmits pure contagion to Belgium, Brazil, Russia and Canada and only receives contagion from the U.K. and

\footnotetext{
9 The contagion effect during the subprime crisis is different from the contagion effect during the sovereign debt crisis.
} 
Germany. Our spatial asymmetry are consistent with the results of Luchtenberg and Vu (2015) because they confirm the existence of both transmitted and received financial pure contagion between markets during the 2008 crisis with different levels of influence.

Table 7 reports the changing features of the dependence series. We can conclude that the transmission effect of the subprime crisis from the U.S. to many mature countries such as France, Switzerland, Germany and Japan, occurred via the traditional transmission channel (Niţoi \& Pochea, 2019), and no pure contagion effect based on the definition proposed by Forbes and Rigobon (2002) was found. This result is consistent with the findings of the study by Zhu et al. (2018), which showed that Japan and Germany were subjected to a serious impact by subprime crisis contagion via the traditional transmission channel. This can be explained by the high levels of dependence between the mature markets in the sample during calm periods, and the fact that spillover effects are determined by fundamental variables such as bilateral trade, FDI and exchange rates, etc. However, a contagion effect transmitted and received between some mature and immature markets, and vice versa between immature markets and between mature markets, were identified. From these unique results, the increase in level of dependence of mature on immature markets arguably began in 2008 (this corresponds to unidirectional pure contagion effect) and, for mature markets, the pure contagion effect began in 2007. The mature markets first received pure contagion effects from the contagious market (U.S.), due to the behavior change of international investors during the crisis. The pure contagion effect resulted from the expectations of international investors and their crowd behavior. This result provides a better understanding of the pure contagion effects which occur during the crisis and the channels of contagion, complementing the study by Wang et al. (2021) which was limited to the foreign exchange market.

No increase in conditional dependencies was identified during the European debt crisis. This absence of pure contagion is due to three reasons. Firstly, mature markets are always highly correlated, and the level of dependence still continued to increase after the global financial crisis. Secondly, the transmission effect of this crisis occurred via fundamental variables such as the channel of credit risks found in the work of Koutmos (2018) as a main channel of spillover effects during the European debt crisis. This may be explained by the high level of economic integration between European financial markets where the work of Sensoy et al. (2019) demonstrates high dependency between EMU markets. Finally, the temporal asymmetry of contagion can be explained by information asymmetries, which are weak between these mature markets (Luchtenberg \& Vu, 2015).

In Tables 6 and 7, we observe a decrease in the conditional dependence level between market indexes before the subprime crisis. However, we also observe how this decrease begins in most cases in 2003, the date from which the US stock markets started to grow again after a long period of decline which followed the burst of the internet bubble in 2000.

Figures 1 and 2 show the conditional dynamic dependencies of the U.S. on other mature and BRICS markets respectively.

\section{Conclusion}

This paper introduces a novel approach for studying contagion effects with the integration of both spatial and temporal asymmetries. To this end, the presence of pure contagion effects between the G10 and BRICS financial markets for the period from 1st January 2001 to 31 May 2018 was examined, with the aim of identifying whether the spillover effects of the recent crisis were due to pure or to fundamentals-based contagion. 
This paper contributes to previous studies on methods used to identify bilateral contagion effects. It proposes a novel methodology based on the conditional static and dynamic copulas and a novel approach to measuring conditional copulas based on conditional empirical distribution functions.

The aim of this study was to quantify the difference between the dependence among financial time series in calm and stress periods. For neighboring markets, the main conclusion drawn was that transmission of the crisis is explained by fundamentals-based contagion due to interconnection during calm periods (Asgharian et al., 2013).

In the first part of this paper, a conditional version of the approach proposed by Durante et al. (2013) was used to take into account the spatial asymmetry of dependence between financial markets, mainly because contagion effects were studied between heterogeneous markets. The second part of this empirical investigation focused on the temporal asymmetry in addition to the space component. A conditional dynamic Gaussian copula in combination with the multiple breakpoints test was used to estimate the structural change of dependence series. In this part, the pure contagion effects of the crises were identified and explained.

This is furthermore the first time that the conditional empirical distribution function has been integrated to estimate empirical conditional copula, with the aim of capturing the spatial asymmetry of contagion phenomena between mature and immature financial markets during the most important two crises of this century. This methodology enabled the direction of contagion effects to be identified. Following this, a dynamic unidirectional dependence to detect the increase in dependence between G10 and BRICS markets was proposed to capture the part of spillover effects which cannot be explained by fundamentals. Pure contagion effect was calculated using the rho level of dependence extracted from conditional dynamic Gaussian copula combined with the multiple breakpoints test synchronized with the increase in level of dependence (Leung et al., 2017).

The present findings explain how the existence of pure contagion with spatial and temporal asymmetries is due to the difference and change in investor behaviors relating to the asymmetry of information on the international financial market.

This study may have some important implications for portfolio managers, policy makers and researchers, as it can enable them to identify the origin, direction and timing of pure financial contagion (Gómez-Puig \& Sosvilla-Rivero, 2016). In particular, for portfolio managers, understanding the bilateral and multilateral behaviors of financial markets opens up more opportunities for portfolio diversification and resource allocation (Changqing et al., 2015). For policy makers, it can help them to adopt appropriate policy measures in order to reduce the vulnerability of their country to an external shock.

For future studies, we propose four possible perspectives from this work:

- Applying the methodology proposed in this paper to test and explain the contagion effects between stock, exchange, bond and commodities markets;

- Applying the methodology proposed in this paper to study sectoral contagion effects, mainly after the COVID-19 pandemic;

- Using the conditional dynamic dependencies series as an endogenous variable in order to distinguish the transmission channels during a crisis of pure contagion from the transmission channels during a crisis of fundamentals-based contagion; and

- Taking the conditional dynamic dependencies series to develop a spatial weight matrix to improve the forecasting of results of stock market returns with a spatial modeling approach. 


\section{References}

Ahmad, W., Sehgal, S., \& Bhanumurthy, N. R. (2013). Eurozone crisis and BRICKS stock markets: Contagion or market interdependence? Economic Modelling, 33, 209-225.

Al Nasser, O. M., \& Hajilee, M. (2016). Integration of emerging stock markets with global stock markets. Research in International Business and Finance, 36, 1-12.

Asgharian, H., Hess, W., \& Liu, L. (2013). A spatial analysis of international stock market linkages. Journal of Banking and Finance, 37(12), 4738-4754.

Asgharian, H., \& Nossman, M. (2011). Risk contagion among international stock markets. Journal of International Money and Finance, 30(1), 22-38.

Ayadi, M., Boudhina, R., Khallouli, W., \& Sandretto, R. (2006). La contagion de la crise asiatique: Dynamiques de court terme et de long terme. Économie Internationale, 105(1), 113-135.

Bai, J., \& Perron, P. (2003). Critical values for multiple structural change tests. Econometrics Journal, 6(1), $72-78$.

Baig, T., \& Goldfajn, I. (1999). Financial Market contagion in the Asian crisis. Palgrave Macmillan Journals on Behalf of the International Monetary Fund, 46(2), 167-195.

Batten, J. A., Kinateder, H., Szilagyi, P. G., \& Wagner, N. F. (2019). Time-varying energy and stock market integration in Asia. Energy Economics, 80, 777-792.

Bekaert, G., Ehrmann, M., Fratzscher, M., \& Mehl, A. (2014). The global crisis and equity market contagion. Journal of Finance, 69(6), 2597-2649.

Bekaert, G., Harvey, C. R., \& Ng, A. (2005). Market integration and contagion. Jounal of business 89.

Billio, M., \& Pelizzon, L. (2003). Contagion and interdependence in stock markets: Have they been misdiagnosed? Journal of Economics and Business, 55(5-6), 405-426.

Bradley, B., \& Taqqu, M. (2004). Framework for analyzing spatial contagion between financial markets. Finance Letters, 2(6), 8-15.

Bradley, B., \& Taqqu, M. (2005a). Empirical evidence on spatial contagion between financial markets. Finance Letters, 3(1), 77-86.

Bradley, B., \& Taqqu, M. (2005b). How to estimate spatial contagion between financial markets. Finance Letters, 3(1), 64-76.

Carol, A. (2008). Market risk analysis Volume II Practical financial econometrics. England: John Wiley \& Sons Ltd The Atrium, Southern Gate, Chichester.

Carrion-I-Silvestre, J. L., Kim, D., \& Perron, P. (2009). GLS-based unit root tests with multiple structural breaks under both the null and the alternative hypotheses. Econometric Theory, 25(6), 1754-1792.

Changqing, L., Chi, X., Cong, Y., \& Yan, X. (2015). Measuring financial market risk contagion using dynamic MRS-Copula models: The case of Chinese and other international stock markets. Economic Modelling, 51, 657-671.

Claeys, P., \& Vašíček, B. (2014). Measuring bilateral spillover and testing contagion on sovereign bond markets in Europe. Journal of Banking and Finance, 46(1), 151-165.

Corsetti, G., Marcello, P., \& Sbracia, M. (2011). Correlation analysis of financial contagion. In Financial Contagion: The Viral Threat to the Wealth of Nations pp. 11-20.

Diebold, F. X., \& Yilmaz, K. (2009). Measuring financial asset return and volatility spillovers, with application to global equity markets. Economic Journal, 119(534), 158-171.

Dornbusch, R., Park, Y. C., \& Claessens, S. (2000). Contagion: Understanding how it spreads. The World Bank Research Observer, 15(2), 177-197.

Durante, F., \& Foscolo, E. (2013). An analysis of the dependence among financial markets by spatial contagion. International Journal of Intelligent Systems, 28, 319-331.

Durante, F., Foscolo, E., Jaworski, P., \& Wang, H. (2014). A spatial contagion measure for financial time series. Expert Systems with Applications, 41(8), 4023-4034.

Durante, F., Foscolo, E., Jaworski, P., \& Wang, H. (2015). Strengthening links between data analysis and soft computing. Advances in Intelligent Systems and Computing, 315, 217-224.

Engle, R. (2009). Anticipating correlations a new paradigm for risk management. In Princeton University Press Princeton and Oxford.

Fernandez, V. (2011). Spatial linkages in international financial markets. Quantitative Finance, 11(2), 237-245.

Filho, O. C. S., Ziegelmann, F. A., \& Dueker, M. (2014). Assessing dependence between financial market indexes using conditional time-varying copulas: Applications to Value at Risk (VaR). Quantitative Finance, 14(12), 2155-2170.

Forbes, K. J., \& Rigobon, R. (2002). No contagion, only interdependence: Measuring stock market comovements. The Journal of Finance, 57(5), 2223-2261. 
Gjika, D., \& Horváth, R. (2013). Stock market comovements in Central Europe: Evidence from the asymmetric DCC model. Economic Modelling, 33, 55-64.

Glasserman, P., \& Young, H. P. (2015). How likely is contagion in financial networks? Journal of Banking and Finance, 50, 383-399.

Gómez-Puig, M., \& Sosvilla-Rivero, S. (2016). Causes and hazards of the euro area sovereign debt crisis: Pure and fundamentals-based contagion. Economic Modelling, 56, 133-147.

Hadhri, S., \& Ftiti, Z. (2019). Asset allocation and investment opportunities in emerging stock markets: Evidence from return asymmetry-based analysis. Journal of International Money and Finance, 93, $187-200$.

Hübsch, A., \& Walther, U. (2017). The impact of network inhomogeneities on contagion and system stability. Annals of Operations Research, 254(1-2), 61-87.

Jayech, S. (2016). The contagion channels of July-August-2011 stock market crash: A DAG-copula based approach. European Journal of Operational Research, 249(2), 631-646.

Kenourgios, D., \& Dimitriou, D. (2015). Contagion of the global financial crisis and the real economy: A regional analysis. Economic Modelling, 44, 283-293.

Kocaarslan, B., Soytas, U., Sari, R., \& Ugurlu, E. (2018). The changing role of financial stress, oil price, and gold price in financial contagion among US and BRIC markets. International Review of Finance, $1-34$.

Koutmos, D. (2018). Interdependencies between CDS spreads in the European Union: Is Greece the black sheep or black swan? Annals of Operations Research, 266(1-2), 441-498.

Leung, H., Schiereck, D., \& Schroeder, F. (2017). Volatility spillovers and determinants of contagion: Exchange rate and equity markets during crises. Economic Modelling, 61, 169-180.

Lin, W., Engle, R. F., \& Ito, T. (1994). Do bulls and bears move across borders? International transmission of stock returns and volatility. Review of Financial Studies, 7(3), 507-538.

Luchtenberg, K. F., \& Vu, Q. V. (2015). The 2008 financial crisis: Stock market contagion and its determinants. Research in International Business and Finance, 33, 178-203.

Naresh, G., Vasudevan, G., Mahalakshmi, S., \& Thiyagarajan, S. (2018). Spillover effect of US dollar on the stock indices of BRICS. Research in International Business and Finance, 44, 359-368.

Niţoi, M., \& Pochea, M. M. (2019). What drives European Union stock market co-movements? Journal of International Money and Finance, 97, 57-69.

Patton, A. (2006). Modeling asymmetric exchange rate dependence. International Economic Review, 47(2), $527-556$.

Patton, A. (2012). A review of copula models for economic time series. Journal of Multivariate Analysis, $110,4-18$.

Patton, A. (2013). Copula methods for forecasting multivariate time series. Handbook of Economic Forecasting, 2, 899-960.

Rigobon, R. (2016). Contagion, spillover and interdependence (No. 1975).

Rodriguez, J. C. (2007). Measuring financial contagion: A Copula approach. Journal of Empirical Finance, $14(3), 401-423$.

Sensoy, A., Nguyen, D. K., Rostom, A., \& Hacihasanoglu, E. (2019). Dynamic integration and network structure of the EMU sovereign bond markets. Annals of Operations Research, 281(1-2), 297-314.

Shen, P. L., Li, W., Wang, X. T., \& Su, C. W. (2015). Contagion effect of the European financial crisis on China's stock markets: Interdependence and pure contagion. Economic Modelling, 50, 193-199.

Sklar, A. (1959). Fonctions de répartition à n dimensions et leurs marges. Publications de l'Institut de Statistique de l'Universit'e de Paris, 8:229-231.

Tam, P. S. (2014). A spatial - temporal analysis of East Asian equity market linkages. Journal of Comparative Economics, 42(2), 304-327.

Wang, G. J., Xie, C., Lin, M., \& Stanley, H. E. (2017). Stock market contagion during the global financial crisis: A multiscale approach. Finance Research Letters, 22, 163-168.

Wang, H., Yuan, Y., Li, Y., \& Wang, X. (2021). Financial contagion and contagion channels in the forex market: A new approach via the dynamic mixture copula-extreme value theory. Economic Modelling, 94(January), 401-414.

Wang, Y. C., Wu, J. L., \& Lai, Y. H. (2018). New evidence on asymmetric return-volume dependence and extreme movements. Journal of Empirical Finance, 45, 212-227.

Wen, X., Wei, Y., \& Huang, D. (2012). Measuring contagion between energy market and stock market during financial crisis: A copula approach. Energy Economics, 34(5), 1435-1446.

Weng, Y., \& Gong, P. (2016). Modeling spatial and temporal dependencies among global stock markets. Expert Systems with Applications, 43, 175-185.

Xiong, Y., Sun, S., Wang, Z., Wang, K., \& Liu, L. (2016). Application of structural breakpoint test to the correlation analysis between crude oil. Open Journal of Business and Management, 4, 322-328. 
Zhang, W., Zhuang, X., \& Lu, Y. (2020). Spatial spillover effects and risk contagion around G20 stock markets based on volatility network. North American Journal of Economics and Finance, 51(C), 101064.

Zhou, Z., Lin, L., \& Li, S. (2018). International stock market contagion: A ceemdan wavelet analysis. Economic Modelling, 72, 333-352.

Zhu, Y., Yang, F., \& Ye, W. (2018). Financial contagion behavior analysis based on complex network approach. Annals of Operations Research, 268(1-2), 93-111.

Zorgati, I., \& Lakhal, F. (2020). Spatial contagion in the subprime crisis context: Adjusted correlation versus local correlation approaches. Economic Modelling, 92, 162-169.

Publisher's Note Springer Nature remains neutral with regard to jurisdictional claims in published maps and institutional affiliations. 